\title{
From $\alpha$-Amino Acids to Peptides: All You Need for the Journey
}

\author{
Carmen Nájera* \\ Departamento de Química Orgánica, Facultad de Ciencias, Universidad de Alicante, Apdo. 99, 03080 Alicante, Spain \\ Fax +34(965)903549; E-mail: cnajera@ua.es \\ Received 10 October 2001
}

\begin{abstract}
In this account several tools necessary for the synthesis of peptides from $\alpha$-amino acids are considered. Different strategies for the asymmetric synthesis of $\alpha$-amino acids are studied. New chiral glycine and alanine imines as acyclic and cyclic templates for the asymmetric synthesis of different types of mono as well as dialkylated $\alpha$-amino acids with acyclic and heterocyclic structures are reviewed. Their diastereoselective alkylation and final hydrolysis takes place under very mild reaction conditions. New polymer-supported cinchonidine and cinchonine ammonium salts and chiral binaphthol-derived aminoalkoxides (BINOLAMs), have been developed as catalysts for the asymmetric PTC alkylation of imino esters. The use of chiral oxazinone and pyrazinone $\alpha, \beta$-didehydroamino acid derivatives in hydrogenation, Heck-arylation, cyclopropanation and Diels-Alder cycloaddition reactions for the asymmetric synthesis of $\alpha$-amino acids are also studied. Azomethine ylides derived from saturated oxazinones can also be used in the asymmetric synthesis of prolines by means of diastereoselective dipolar cycloadditions. For the protection of $\alpha$-amino acids new efficient reagents, Fmoc-P-OSu and Cbz-P-OSu, derived from poly(styrene-co- $N$-hydroxymaleimide) named as polymeric $N$-hydroxysuccinimide (P-HOSu), have been developed. Several new systems such as polymer-supported $\mathrm{P}-\mathrm{HOSu} / \mathrm{DCC}$ and polystyrenebound P-TBTU or P-HBTU, together with non- polymeric thiouronium salts derived from 2-mercaptopyridine-1-oxide and TMU, such as HOTT and TOTT, and from DMPU, such as HODT and TODT, have been used as peptide coupling reagents, in solution and solid phase peptide synthesis, as well as for the preparation of primary amides, Weinreb amides and other hydroxamates, directly from carboxylic acids.
\end{abstract}

1 Introduction

2 Asymmetric Synthesis of $\alpha$-Amino Acids

2.1 Electrophilic Alkylation of Chiral Glycine and Alanine Templates

2.2 Electrophilic Alkylation with Chiral Phase-transfer Catalysts

2.3 Chiral $\alpha, \beta$-Didehydroamino Acid Derivatives

2.4 Chiral Azomethine Ylides

3 Protecting-group Reagents

$4 \quad$ Peptide Coupling Reagents

5 Conclusion

Key words: amino acids, phase-transfer catalysis, asymmetric catalysis, protecting groups, peptides

\section{$1 \quad$ Introduction}

The developments in the important field of peptide chemistry ${ }^{1}$ is linked to advances in several synthetic methodologies, mainly: (a) the asymmetric synthesis of $\alpha$-ami-

Synlett 2002, No. 9, Print: 02092002.

Art Id.1437-2096,E;2002,0,09,1388,1403,ftx,en;A29301ST.pdf.

(c) Georg Thieme Verlag Stuttgart · New York

ISSN 0936-5214 no acids, especially for the non-proteinogenic compounds, ${ }^{2}$ (b) the discovery of appropriate protecting groups for $\alpha$-amino acids ${ }^{3}$ and (c) the development of effective coupling techniques either in solution or in solidphase by means of peptide coupling reagents. ${ }^{1,4}$ These areas of interest have attracted the attention of organic chemists and have revolutionized many aspects of organic synthesis. For instance, solid-phase synthesis, introduced by Merrifield for peptides, has expanded into the area of combinatorial chemistry and has encouraged the development of new polymers and linker systems. The asymmetric synthesis of $\alpha$-amino acids has brought the discovery of numerous chiral auxiliaries in stoichiometric and substoichiometric versions, together with a plethora of strategies as well as many biotransformations. The structural diversity of $\alpha$-amino acids as well as the different reaction conditions for the coupling process requires the use of almost tailormade synthetic strategies, protecting groups and coupling reagents.

In the last five years our group has been involved in synthetic work related to $\alpha$-amino acids and peptides. This account summarizes our work, mainly concerning the design of new chiral glycine and alanine templates and also chiral phase-transfer-catalysts (PTC), for the stochiometric and substoichiometric asymmetric syntheses, of different types of $\alpha$-amino acids via alkylation reactions and other methodologies. Our aim was to find simple and mild reaction conditions, mainly in the alkylation of the corresponding enolates and during the usually tricky final hydrolysis step. More recently, we have entered into the design of new protecting group and peptide coupling reagents searching for effectiveness, but also for scalable syntheses and economically favourable products, moving ourselves to applied green chemistry.

2

\section{Asymmetric Synthesis of $\alpha$-Amino Acids}

From recent reviews, mainly published in the last decade, ${ }^{2}$ one can deduce that there are five general well-established strategies for the asymmetric synthesis of $\alpha$-amino acids: (a) the classic enzymatic synthesis, (b) hydrogenation or cycloaddition reactions of $\alpha, \beta$-didehydroamino acid derivatives, (c) Strecker-type synthesis, (d) electrophilic or nucleophilic aminations and (e) electrophilic or nucleophilic alkylations.

The electrophilic alkylation of enolates derived from chiral glycine or alanine templates has become the most versatile and prolific method for the asymmetric synthesis 
of acyclic and heterocyclic $\alpha$-amino acids. In the last 20 years several types of reagents with acyclic and cyclic structures have been developed. Some of the most efficient and popular templates are the cyclic Schöllkopf's bis(lactim) ethers 1, Seebach's oxazolidinones and imidazolidinones $\mathbf{2}$ and Williams' morpholinones $\mathbf{3}$. As acyclic systems, Belokon's nickel complexes 4, Oppolzer's sultam derivatives 5 and Myers' pseudoephedrine glycinamides 6 can be mentioned (Figure 1). One of the major inconveniences of the use of these systems is that the enolization has to be carried out generally with strong anionic bases (BuLi, LDA, LiHMDS, etc.), very low temperatures, and strict anhydrous conditions. These extreme reaction conditions are not useful for large scale synthesis. Our initial goal was to design easily enolizable chiral glycine and alanine templates with acyclic or cyclic structures. For this purpose we focused our attention on imines derived from aromatic aldehydes or ketones, both as protecting and activating moieties at the nitrogen of glycine and alanine derivatives. ${ }^{5}$ These type of reagents are easily enolizable according to their $\mathrm{pK}_{\mathrm{a}}$ values, ${ }^{6}$ allowing the use of PTC conditions ${ }^{7}$ for the alkylation step, even being allylated under $\operatorname{Pd}(0)$ catalysis. ${ }^{8}$ Moreover, this type of compound can be hydrolyzed under very mild conditions and the chiral auxiliary can be located on the glycine or alanine template (Section 2.1) or can be an external reagent, for instance a chiral phase-transfer catalyst ${ }^{5}$ (Section 2.2).

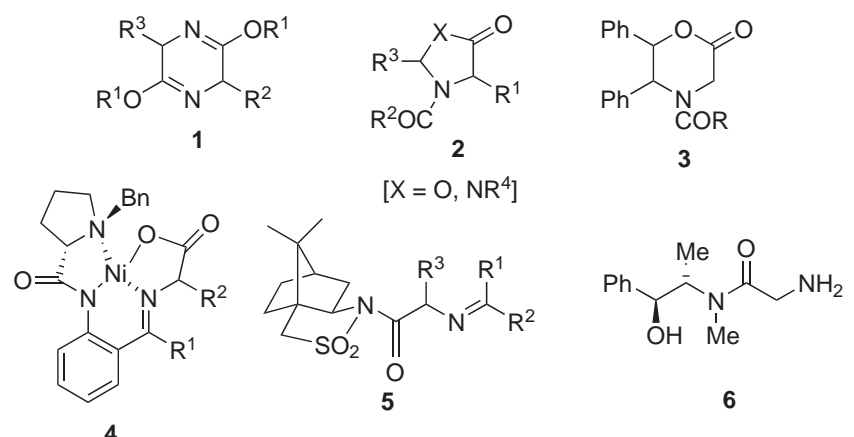

Figure 1

\section{1 \\ Electrophilic Alkylation of Chiral Glycine and Alanine Templates}

The preparation of chiral Schiff bases derived from glycine or alanine is in general very simple, requiring just the condensation with a carbonyl compound or its imine. Another advantage of these systems is that they can be easily hydrolyzed to furnish the corresponding amino acid after the alkylation step. The availability of ephedrine imidazolidinones, which have been proven to be very efficient chiral auxiliaries, ${ }^{9}$ and the possibility of their recovery prompted us to prepare the glycinimide derivatives $\mathbf{7}$ and 8. For the preparation of these reagents, the imidazolidinone was acylated with $\alpha$-chloroacetyl chloride and the glycine structure was completed through the intermediate azide, followed by hydrogenation $(\mathrm{Pd} / \mathrm{C})$ and final formation of the imines. ${ }^{10}$ They are crystalline compounds stable at room temperature, although the benzophenone derivative $\mathbf{8}$ is sensitive to acidic media as well as to silica gel. Therefore, they could not be prepared by direct trimethylaluminium-mediated acylation of the imidazolidinones with methyl imino esters as in the case of Oppolzer's sultam-derived glycinimides..$^{11}$ The alkylation process, initially studied with $N$-[bis(methylthio)methylene]glycinimide $7,{ }^{10 a}$ was very disappointing. It suffered cleavage of the $N$-acyl group under solid-liquid PTC conditions: potassium carbonate or potassium hydroxide in acetonitrile and tetrabutylammonium bromide (TBAB) as catalyst at room temperature. When aprotic alkylation conditions were assayed with compound $\mathbf{7}$, using bases such as lithium hexamethyldisilazide or potassium tertbutoxide in THF at low temperatures in the presence of lithium chloride, the alkylation with activated alkyl halides took place diastereoselectively in $58-86 \%$ yield and $76-96 \%$ de. From these preliminary studies, we deduced not only the crucial influence of lithium chloride in both chemical yield and diastereoselectivity, but also that the temperature was critical in the cleavage of the imide bond. Thus, when the alkylation of compounds 7 and 8 was carried out under PTC conditions at $-20^{\circ} \mathrm{C}$ with lithium hydroxide in the presence of lithium chloride and TBAB in acetonitrile, the reaction with activated alkyl halides gave

\section{Biographical Sketch}

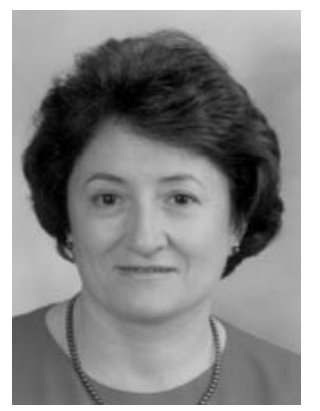

Carmen Nájera was born in Nájera (La Rioja) and graduated from the University of Zaragoza in 1973, obtaining her doctorate in chemistry from the University of Oviedo in 1979. She carried out postdoctoral work with Prof. D. Seebach at the ETH (Zürich), Prof. J. E. Baldwin at the Dyson Perrins Laboratory (Ox- ford), Prof. E. J. Corey at Harvard University and Prof. J.-E. Bäckvall at Uppsala University. She became Associate Professor in 1985 at the University of Oviedo and full Professor in 1993 at the University of Alicante. She has been a visiting professor at the University of Arizona (USA) and Universidad Nacional del Sur (Ar- gentina). She is co-author of more than 130 papers and 15 reviews. Her current research interest is focused on organometallic chemistry, sulfones, amino acids, asymmetric synthesis, protecting-group reagents, peptide coupling reagents, solid-phase synthesis and palladium-mediated catalysis. 
products 10 or 11 in 55-90\% yield and 84-94\% de (Equation 1). The effect of lithium chloride is illustrated in $Z$ enolates 9, lithium acting as chelating cation changes the degree of aggregation and also its conformation. ${ }^{12}$ Lithium chloride is a Lewis acid that can also activate electrophiles and has a general effect on the polarity of the solvent. ${ }^{13}$ Reagent 8 gave higher diastereoselectivities than $\mathbf{7}$ and was preferred in order to avoid unpleasant carbon disulfide. The benzophenone glycinimide 8 was alkylated in the presence of organic bases such as 1,8diazabicyclo[5.4.0] undec-7-ene (DBU), tetramethylguanidine (TMG) or 2-tert-butylimino-2-diethylamino1,3-dimethylperhydro-1,3,2-diazaphosphorine (BEMP) ${ }^{14}$ combined with lithium chloride in acetonitrile at $-20{ }^{\circ} \mathrm{C}$. DBU was the base of choice because it gave better chemical yields and de in shorter reaction times, even better than under PTC conditions. Activated alkyl halides and electrophilic olefins can be used as electrophiles, working in the last case with 0.1 equivalents of base. Alkylated products 11 were isolated after acid/base extractive workup in 25-95\% yield and 70-98\% de.

Two procedures can be employed for the final hydrolysis step. In the case of the $N$-bis(methylsulfanyl)methylene derivatives 10, the imide cleavage was achieved with lithium hydroperoxide in $\mathrm{THF} / \mathrm{H}_{2} \mathrm{O}(3: 1)$ to give the chiral auxiliary in $87-90 \%$ yield, whereas the imine hydrolysis was performed with $1 \mathrm{M}$ hydrochloric acid. Free amino acids 12 were isolated after treatment with propylene oxide. For products $\mathbf{1 1}$ the most convenient conditions involved the use of refluxing in water affording, after simple extractive work-up, recovered (-)-imidazolidinone (95$99 \%$ ) and $(S)$ - $\alpha$-amino acids 12 such as allylglycine, prenylglycine, phenylalanine, 3,4-(methylenedioxy)phenylalanine, pyroglutamic and 2-(tert-butoxycarbonylamino)-5-oxohexanoic acids in $45-87 \%$ yield and 66$96 \%$ ee. Other hydrolysis conditions allowed the $N$-Bocand $N$-Fmoc-protected amino acids and esters to be obtained. ${ }^{10 \mathrm{c}}$

The alkylation of the glycine template (-)-8 has been applied to the synthesis of heterocyclic $\alpha$-amino acids such as (-)-baikiain $\mathbf{1 3}$ and the tetrahydroisoquinoline deriva- tive 14 by using $(Z)$-1,4-dichloro-2-butene and $\alpha, \alpha^{\prime}$-dibromo- $O$-xylene as dielectrophiles, respectively (Figure 2 ). Moreover, starting from the (+)-ephedrine-derived imidazolidinone the corresponding benzophenone glycinimide (+)-8 has been prepared in 54\% overall yield, this compound being used for the preparation of $(R)$ - $\alpha$-amino acids by means of DBU-LiCl mediated alkylation followed by hydrolysis in refluxing water. ${ }^{10 \mathrm{c}}$
13<smiles>O=C1CC=CCN1</smiles><smiles>O=C([O-])C1Cc2ccccc2C[NH2+]1</smiles>

14
Figure 2

At that point we decided to prepare imines derived from Myers' (+)-pseudoephedrine glycinamide $6,{ }^{15}$ expecting a higher stability of the amide bond during the basic conditions of the alkylation step. For the synthesis of imine 15, (+)-pseudoephedrine was deprotonated with $\mathrm{BuLi}-\mathrm{LiCl}$ and condensed with commercially available $N$-[bis(methylsulfanyl)methylene]glycine methyl ester at $0{ }^{\circ} \mathrm{C} .{ }^{16} \mathrm{Com}-$ pound 15 could be isolated in $71 \%$ yield, but the synthesis of related benzophenone imine $\mathbf{1 6}$ took place in low yield $(<20 \%)$. The alkylation process could only be carried out with glycinamide $\mathbf{1 5}$ under PTC conditions, but using strong bases such as sodium hydride, lithium tert-butoxide, potassium tert/butoxide, or sodium ethoxide in THF at room temperature. Under these conditions, O-alkylation at the hydroxy functionality of the chiral auxiliary, observed when potassium hydroxide, caesium hydroxide, or potassium carbonate were used as bases, could be avoided (Equation 2). Activated alkyl halides were employed as electrophiles, alkoxides lithium tert-butoxide (1 equiv) or sodium ethoxide (3 equiv), in the presence of TBAB, giving the highest de's (66-94\%) and isolated yields $(36-72 \%)$.

The observed diastereofacial bias was the same as in the case of Myers' glycinamide 6. In the proposed model the lithium cation of the alkoxide coordinates to two mole-

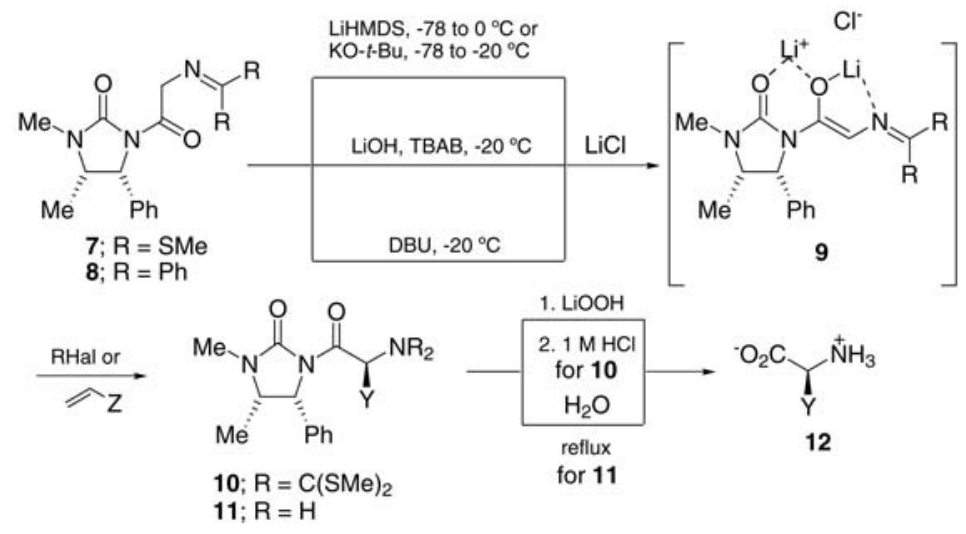

Equation 1 


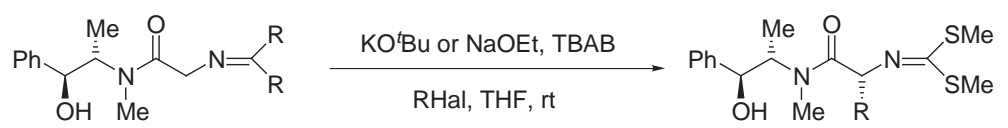

15; $\mathrm{R}=\mathrm{SMe}$

16; $\mathrm{R}=\mathrm{Ph}$

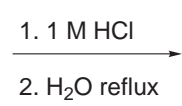

$\underset{\text { 2. } \mathrm{H}_{2} \mathrm{O} \text { reflux }}{\stackrel{1.1 \mathrm{M} \mathrm{HCl}}{\longrightarrow}}$
17
$\mathrm{O}_{2} \mathrm{C} \underset{\mathrm{B}}{\stackrel{\mathrm{N}}{\mathrm{N}} \mathrm{H}_{3}}$

12

Equation 2

cules of the solvent (THF) blocking one of the faces of the $Z$-enolate. ${ }^{15 \mathrm{c}} \mathrm{We}$ have performed ab initio calculations on the enolate ${ }^{17}$ at the RHF/6-31G(d) theory level ${ }^{18}$ and its optimized geometry confirms the proposed reactive conformation for the enolate of reagent 6.

For the synthesis of $\alpha$-methyl- $\alpha$-amino acids (AMAAs), important compounds in medicinal chemistry, the most direct pathway is the alkylation of enolates derived from alanine templates. In the case of alanine acyclic reagents, the imino group should derive from an aldehyde. Very poor results were observed in our initial attempts to alkylate ephedrine-imidazolidinone or pseudoephedrine alanine templates with the amino group protected with benzaldehyde or $p$-chlorobenzaldehyde, probably due to steric reasons. However, we found that cyclic imine templates from alanine, with structure of 3,6-dihydro- $2 \mathrm{H}-1,4-$ oxazin-2-one 18 and 1,2,3,6-tetrahydro-2-pyrazinone $\mathbf{1 9}$, are very efficient substrates for the quaternization of the alanine enolate. ${ }^{19}$ These heterocyclic reagents, which bear a phenyl group at the 5-position, have a highly acidic alanine hydrogen at the 3-position, which after deprotonation should give a stabilized azaenolate. Moreover, the isopropyl group at the 6-position can generate 1,4-asymmetric induction through a blocking effect of one of the two diastereotopic faces of the enolate, sterically protecting at the same time the deprotonation of the hydrogen at this position. Our primary studies were dedicated towords investigating the synthesis of oxazinones following a procedure described for the racemic systems. ${ }^{20}$ Thus, $\alpha$-bromoisovalerophenone was treated with the potassium salt of $\mathrm{N}$ Boc-L-alanine in DMF and the resulting diasteromeric esters were separated by recrystallization and/or flash chromatography. After $N$-Boc-deprotection and formation of the imine the (6R)-trans-oxazinone was obtained and only slight epimerization at C-3 was detected (dr 20:1), which is unimportant because this carbon atom will become planar after the formation of the enolate. ${ }^{21}$ Unfortunately, the (6S)-cis-oxazinone also suffered epimerization at C-6 and could not be used further for the synthesis of $(R)$-AMAAs. Nevertheless, starting from $N$-Boc-D-alanine, the corresponding (6S)-trans-oxazinone was prepared following the same protocol. ${ }^{21 \mathrm{c}}$ The relative configuration of transoxazinones was determined by NMR and X-ray diffraction analysis. ${ }^{21 a}$ The related trans-pyrazinone ${ }^{22} 19$ was prepared in $69 \%$ overall yield by reaction of $(R)-\alpha$-aminoisovalerophenone hydrochloride, easily accesible from D-valine, with mixed $N$-Boc-L-alanine-pivalic anhydride followed by cyclization and finally $N$-Boc protection (Scheme 1). ${ }^{23}$ Pyrazinone 19 was obtained in the same diastereomeric ratio as oxazinone 18, what means that both heterocycles have similar acidity at C-3. Semiempirical calculations on the optimised model of lithium enolates of $18^{21 \mathrm{c}}$ and $1^{23 \mathrm{~b}}$ showed the blocking effect of the, almost perpendicular, isopropyl group to the ring in both reagents.

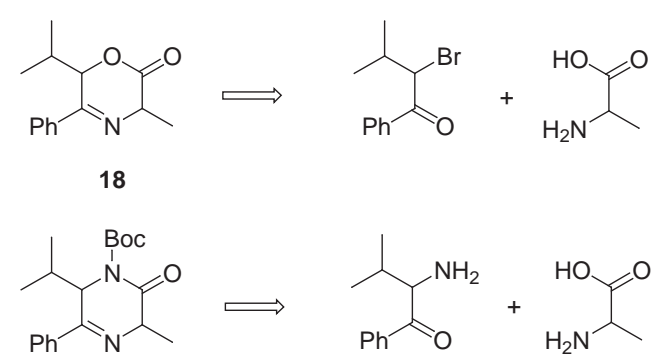

19

Scheme 1

These heterocyclic reagents could be alkylated at room temperature under very mild reaction conditions, either with potassium carbonate as base under solid-liquid PTC conditions in acetonitrile or in the presence of organic bases such as DBU or BEMP and lithium iodide in $N$-methylpyrrolidone. Under PTC conditions, activated alkyl halides and electrophilic olefins gave good yields (60$75 \%$ for oxazinones and $44-86 \%$ for pyrazinones) and diastereoselectivities (84-96\% for oxazinones and 95$98 \%$ for pyrazinones). Both reagents reacted with formaldehyde under PTC conditions to afford the addition products 20 and $21\left(\mathrm{Y}=\mathrm{CH}_{2} \mathrm{OH}\right)$ in $63 \%$ and $71 \%$ yield, and with $60 \%$ and $81 \%$ de, respectively (Equation 3). In general, pyrazinones are more stable than oxazinones towards purification protocols and gave better yields and de, by contrast oxazinones are more readily accesible. BEMP is the base of choice for oxazinones when unactivated alkyl halides were used as electrophiles, ${ }^{21 b, c}$ the reaction taking place in short times (ca. $1 \mathrm{~h}$ ), with $>96 \%$ de and moderate yields (38-65\%). For pyrazinones, stoichiometric amounts of DBU should be used for alkyl halides and 10 mol\% for Michael additions affording products 21 in 49$84 \%$ yield and $95-98 \%$ de. ${ }^{23 b}$ The presence of lithium iodide is important for both systems, since it prevents $\mathrm{O}$ alkylation in the case of oxazinones and the homocoupling of the enolate for pyrazinones. ${ }^{21 \mathrm{~b}, \mathrm{c}}$ The relative con- 


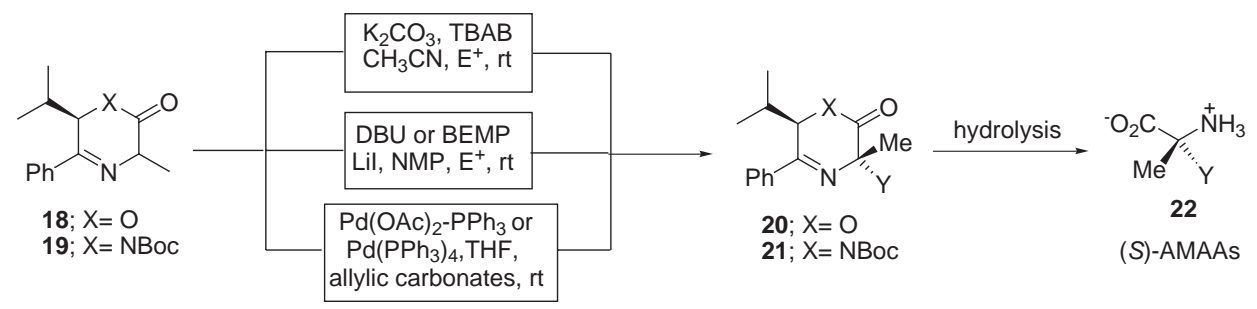

\section{Equation 3}

figuration of the obtained alkylated products $\mathbf{2 0}$ and $\mathbf{2 1}$ was confirmed by NOE experiments and by X-ray diffraction analysis in the case of $\mathbf{2 0}\left(\mathrm{Y}=\mathrm{CH}_{2} \mathrm{C} \equiv \mathrm{CH}\right)$.

The third possibility is the allylation of glycine or alanine enolates under $\operatorname{Pd}(0)$-catalysis. This process has been carried out previously only with LDA-generated enolates from Oppolzer's benzophenone glycinimine 5. ${ }^{24}$ Surprisingly, in the case of oxazinone $\mathbf{1 8}^{21}$ and pyrazinone $\mathbf{1 9}^{23}$ the diastereoselective allylation took place under neutral conditions by using allylic carbonates in the presence of $\mathrm{Pd}\left(\mathrm{PPh}_{3}\right)_{4} \quad(5 \mathrm{~mol} \%)$ and 1,2-bis(diphenylphosphanyl)ethane (dppe) $(14 \mathrm{~mol} \%)$ or $\mathrm{Pd}(\mathrm{OAc})_{2}$ and $\mathrm{PPh}_{3}(10$ $\mathrm{mol} \%)$ at room temperature in THF. These reaction conditions failed in the case of imidazolidinone glycinimides 8 probably due to steric reasons. ${ }^{25}$ The reaction takes place in $53-69 \%$ for oxazinones and $64-85 \%$ yields for pyrazinones, with $70-96 \%$ and $98 \%$ de, respectively. When unsymmetrically substituted allylic carbonates were employed, the attack of the enolate took place mainly or exclusively at the less substituted position on the $\left(\eta^{3}-\right.$ allyl)palladium complex and the resulting double bound was obtained with $E$-configuration. In the case of pyrazinone 19, the addition to vinyloxirane was regio- and diastereoselective by using $\mathrm{Pd}(\mathrm{OAc})_{2}$ and dppe, the corresponding (E)-allylic alcohol 21 ( $\mathrm{Y}=$ $\left.\mathrm{CH}_{2} \mathrm{CH}=\mathrm{CHCH}_{2} \mathrm{OH}\right)$ being obtained in $77 \%$ yield and $98 \%$ de. $^{23 b}$

The most difficult task in the asymmetric synthesis of $\alpha, \alpha$ dialkylated $\alpha$-amino acids, such as AMAAs $\mathbf{2 2}^{26}$ is the final hydrolysis of the corresponding precursors. In the case of alkylated oxazinones $\mathbf{2 0}$ and pyrazinones $\mathbf{2 1}$ it was possible to perform the hydrolysis with $6 \mathrm{M}$ aqueous $\mathrm{HCl}$ at $150^{\circ} \mathrm{C}$ (pressure tube) for $1 \mathrm{~d}$ followed by precipitation of the free $(S)$-AMAAs 22 by using propylene oxide. Some representative examples such as $\alpha$-MePhe, $\alpha$-MeAsp, $\alpha$ MeTrp, $\alpha$-MeSer, $\alpha$-MeGlu, and $\alpha$-MeLeu were prepared in high enantiomeric excesses and good yields. In the case of the enantiomeric $(6 S)$-oxazinone 18, the corresponding $(R)$-AMAAs, $\alpha$-MePhe, $\alpha$-MeAsp, $\alpha$-MeGlu, and $\alpha$-Iva were obtained. ${ }^{21 \mathrm{~b}}$ For the hydrolysis to $\alpha$-allylalanine the use of milder reaction conditions was necessary. Thus, in the case of the oxazinone $\mathbf{2 0}(\mathrm{Y}=$ allyl) the imine was firstly hydrolysed with $2 \mathrm{M} \mathrm{HCl}$ in THF at room temperature for $3 \mathrm{~h}$, followed by the ester hydrolysis with aqueous $\mathrm{LiOH}$ in THF at room temperature for $12 \mathrm{~h}$. Finally, the amino acid was purified by Dowex column chromatography and isolated in $57 \%$ yield and $93 \%$ ee. ${ }^{21 \mathrm{a}, \mathrm{b}}$ However, for the pyrazinone derivative 21 ( $\mathrm{Y}=$ allyl) a mixture of $0.75 \mathrm{M}$ hydrochloric acid, acetic acid, toluene and Dowex was heated at $100{ }^{\circ} \mathrm{C}$ during 4 days to give $(S)$ $\alpha$-allylalanine in $62 \%$ yield and $98 \%$ ee (Equation 3 ). ${ }^{23 b}$

The dialkylation of oxazinone 18 and pyrazinone 19 with dihalides was studied for the asymmetric synthesis of heterocyclic AMAAs. Only oxazinone 18 underwent $C$ and $\mathrm{N}$-dialkylation in the presence of BEMP to afford the corresponding products 23 and 24 (55\% and 60\% yield), or under PTC conditions for $\mathbf{2 5}(80 \%)$ in $>98 \%$ de. After the appropriate hydrolysis, optically pure cyclic $(S)$-AMAAs 26-28 were obtained in $73-81 \%$ yield. $^{21 b, c}$

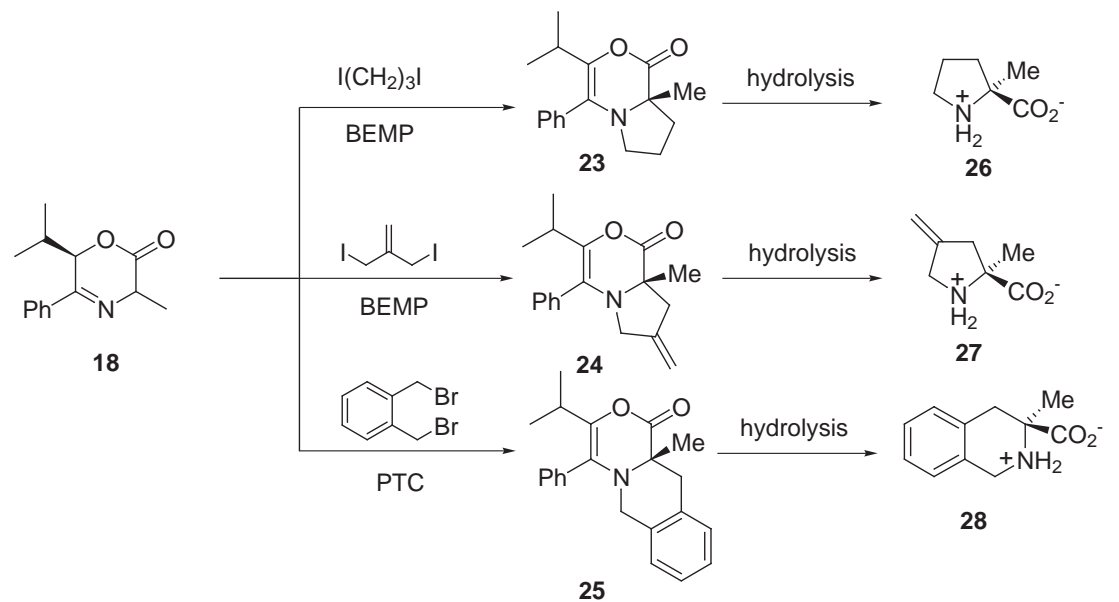

Equation 4 


\subsection{Electrophilic Alkylation with Chiral Phase- Transfer Catalysts}

Other groups in this field were inspired by the pioneering work of O'Donnell's and Grabowski's groups ${ }^{27}$ using tetraalkylammonium halides derived from Cinchona alkaloids cinchonidine 29 and cinchonine $30\left(\mathrm{R}^{1}=\mathrm{Bn}\right.$, $\mathrm{R}^{2}=\mathrm{H}$, allyl, Bn), as PTC catalysts in the monoalkylation of benzophenone-imine glycinates for the synthesis of $(R)$ and $(S)$ - $\alpha$-amino acids, respectively, with $42-81 \%$ ee. ${ }^{5}$ Corey's ${ }^{28}$ and Lygo' ${ }^{29}$ groups could improve the ee up to 99.5\% with $\mathrm{R}^{1}=$ anthracenylmethyl. Modified ammonium salts 29 and $\mathbf{3 0}$ were used with, cesium hydroxide in dichloromethane at a temperature between -78 and -60 ${ }^{\circ} \mathrm{C}^{28}$ and, potassium hydroxide in toluene at room temperature, ${ }^{29}$ respectively. Chiral binaphthol derived ammonium salts $\mathbf{3 1}^{30}$ with $\mathrm{KOH}$ in toluene at room temperature or cesium hydroxide at $0{ }^{\circ} \mathrm{C}$ have been used for the preparation of $(R)$-AAs or $(R)$-AMAAs in ee up to $96 \%$ or $99 \%$. NOBIN 32 and TADDOLs $s^{31} 33$ ligands $^{32}$ as well as chiral salen-metal complexes $\mathbf{3 4}{ }^{33}$ have been used for the synthesis of AMAAs with ee's up to 93\% (Figure 3). Very recently, NOBIN 32 has also been used for the asymmetric synthesis of AAs with high ee. ${ }^{34}$ The search for novel chiral PTC catalysts is still an important challenge..$^{35,36}$

We focused our attention on polymer-supported catalysts derived from Cinchona alkaloids, the most accessible ammonium salts, ${ }^{37}$ in order to achieve an easy separation and recovery of the PTC catalyst. Cinchonidine and cinchonine were alkylated with Merrifield resin ${ }^{38}$ to the corresponding ammonium salts $\mathbf{3 5}$ and $\mathbf{3 6}$ (Equation 5). The enantioselective alkylation of isopropyl glycinate benzophenone imine $\mathbf{3 7}$ was carried out in toluene in the presence of $25 \%$ aqueous sodium hydroxide at $0{ }^{\circ} \mathrm{C}$ with different activated alkyl halides and with catalysts $\mathbf{3 5}$ and 36. ${ }^{39}$ Monoalkylated products 38 were obtained in 70 $95 \%$ yield and the corresponding ( $S$ )-AAs in up to $90 \%$ ee with catalyst $\mathbf{3 5}$ and $(R)$-AAs in up to $40 \%$ ee in the case of polymer 36. The origin of the enantioselectivity is based on the close contact between the enolate and the chiral ammonium salt according to the $\mathrm{X}$-ray structure of $O$-(9)-allyl- $N$-(9-anthracenylmethyl)cinchonidinium

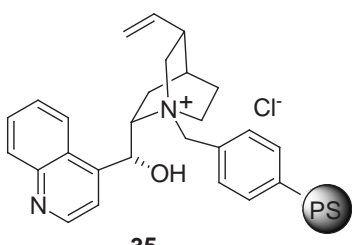

35

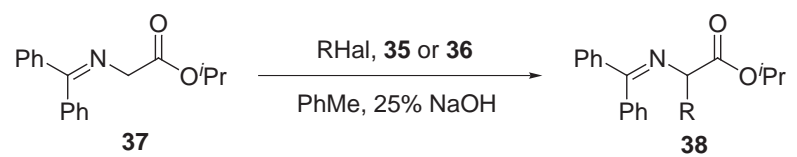

Equation 5

$p$-nitrophenoxide. ${ }^{28 a}$ The model proposed by Corey explains the efficient blocking of one of the faces of the enolate by the ammonium salt.

We have used (aminomethyl)binaphthols 40 related to NOBIN catalysts $\mathbf{3 2}$ for the enantioselective alkylation of enolates derived from aldimines of alaninates by formation of chiral ion pairs (Equation 6) ${ }^{33}$ This type of hydrophobic amino phenols can act as chelating agents for alkali ions and therefore the ion-pairs can be soluble in organic solvents. Different (S)-bis(aminomethyl)binaphthols [ $(S)$-BINOLAMs $4 \mathbf{4 0}$ were prepared in $53-58 \%$ overall yield from diacid $(S)$-39, which was prepared by homocoupling of methyl 3-hydroxy-2-naphthalenecarboxylate ${ }^{40}$ and further resolution with L-leucine methyl ester. ${ }^{41}$

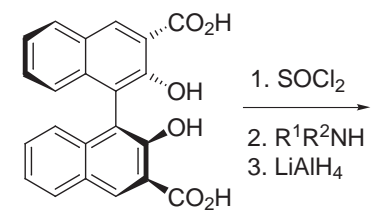

(S) -39

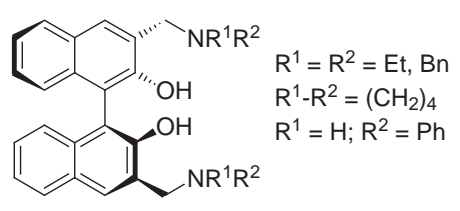

(S)-40 BINOLAMs

\section{Equation 6}

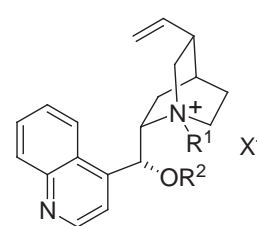

29

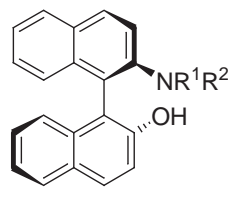

32
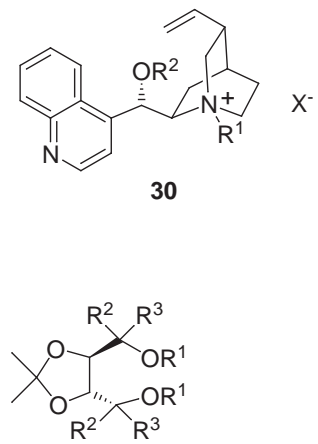

33

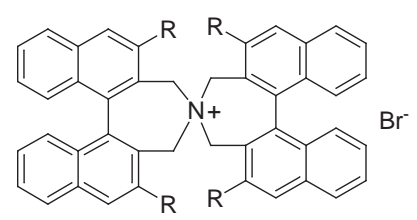

31

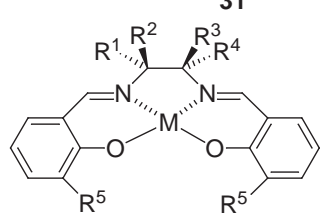

34

Figure 3 
These optically active ligands $\mathbf{4 0}$ were used in the alkylation of several aldimines of isopropyl alaninate 41 with benzyl bromide as electrophile and sodium hydroxide (3 equiv) in toluene at room temperature being the best reaction conditions (Equation 7)..$^{42}(S)$ - $\alpha$-MePhe was isolated in $85 \%$ yield and $68 \%$ ee after hydrolysis using the diethylamine derivative $(S)-\mathbf{4 0}\left(\mathrm{R}^{1}=\mathrm{R}^{2}=\mathrm{Et}\right)$ as phasetransfer catalyst (5 mol\%).<smiles>[R]C=NC(C)C(=O)OCC</smiles>

41

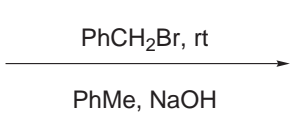

(S)-40 BINOLAMs

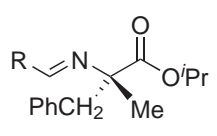

42
Equation 7

After these preliminary promising results we are now studying further applications of these aminophenols as catalysts in asymmetric synthesis.

\subsection{Chiral $\alpha, \beta$-Didehydroamino Acid Derivatives}

Chiral $\alpha, \beta$-didehydroamino acid (DDAA) derivatives ${ }^{43}$ are important building blocks for the synthesis of acyclic amino acids by hydrogenation reactions. ${ }^{44,2 f}$ Moreover, they are especially suitable compounds for cyclopropanation and cycloaddition reactions affording 1-aminocyclopropane-1-carboxylic acids (ACCs) ${ }^{21,45}$ and cyclic and bicyclic $\alpha$-amino acids. ${ }^{21}$ For the synthesis of chiral cyclic DDAA derivatives $\mathbf{4 3}$ and 44, Horner-WadsworthEmmons olefination conditions are used after preparation of the corresponding cyclic glycine phosphonates (Figure 4). In the case of derivatives 45 and $\mathbf{4 6}$, condensation with aldehydes under strong basic conditions must be used. We have developed a preparation of chiral cyclic DDAA derivatives with the structure of oxazinone and pyrazinone bearing an imine function, under mild condensation conditions, in order to study their applications to the asymmetric synthesis of $\alpha$-amino acids.

L-Valine-derived $(S)$-2-hydroxy and $(S)$-2-aminoisovalerophenone were used for the preparation of chiral glycine templates oxazinone 47 and pyrazinone 48, respectively (Scheme 2). In the case of oxazinone $47,(S)$-2-hydroxyisovalerophenone was allowed to react with $N$-Boc-glycine under DCC conditions followed by deprotection with hydrogen chloride and subsequent trimethylamine-mediated cyclization affording 47 in $53 \%$ overall yield. ${ }^{46}$ For the synthesis of pyrazinone $\mathbf{4 8}$ the same strategy as for the alanine derivative 19 was employed, providing the corresponding glycine derivative in $78 \%$ overall yield. ${ }^{47}$

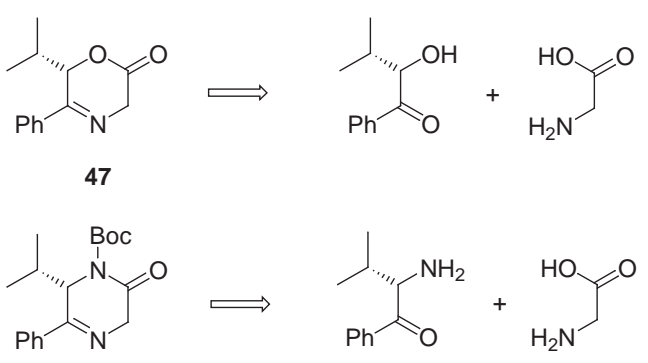

48

Scheme 2

The Knoevenagel-type condensation of these glycine templates with aldehydes took place with potassium carbonate as base and TBAB as phase-transfer catalyst in acetonitrile at room temperature to furnish diasteroselectively (Z)-DDAA derivatives $\mathbf{4 9}(50-64 \% \text { yield })^{46}$ and $\mathbf{5 0}$ $(47-88 \%){ }^{47}$ Dehydroalanine derivatives $\mathbf{5 1}^{46}$ and $\mathbf{5 2}^{47}$ were obtained by simple reaction of glycine templates $\mathbf{4 7}$ and 48 with Eschenmoser's salt at room temperature in $50 \%$ and $88 \%$ yield, respectively (Equation 8 ). In the case of glycine-derived pyrazinone $\mathbf{4 8}$, it was also possible to carry out the condensation with tert-butoxybis(dimethylamino)methane (Bredereck's reagent) or even with inexpensive $N, N$-dimethylformamide dimethylacetal in 1,2dimethoxyethane (DME) at $75{ }^{\circ} \mathrm{C}$ to provide diastereoselectively enaminone ( $Z$ ) $-\mathbf{5 3}$ in $96 \%$ and $95 \%$ yield, respectively.

Pyrazinone DDAA derivatives $\mathbf{5 0}$ could also be prepared by Heck reaction of the dehydroalanine derivative $\mathbf{5 2}$ and by vinylic substitution onto enaminone $\mathbf{5 3}$ (Equation 9). ${ }^{47 \mathrm{~b}}$ The coupling of aryl iodides with the methylenepyrazinone $\mathbf{5 2}$ took place diastereoselectively under Jeffery's conditions, ${ }^{48}$ using palladium(II) acetate $(5 \mathrm{~mol} \%)$ and triphenylphosphine (10 mol\%) as catalyst in the presence of tetrabutylammonium bromide and potassium carbonate in refluxing acetonitrile in $54-70 \%$ yield. The oxazinone derivative $\mathbf{5 1}$ decomposed under similar reaction conditions. Enaminone $\mathbf{5 3}$ can act as $\beta$-acylvinyl cation equivalent ${ }^{49}$ reacting with Grignard reagents or under Barbier conditions ${ }^{50}$ affording diastereoselectively (Z)DDAA derivatives $\mathbf{5 0}$ in 31-60\% yield.

Hydrogenation reaction only took place with oxazinone DDAA derivatives 49. Higher diastereoselectivities were

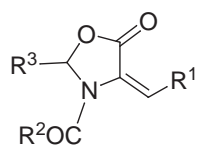

43

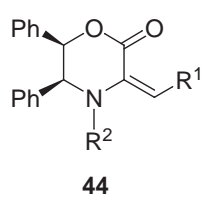

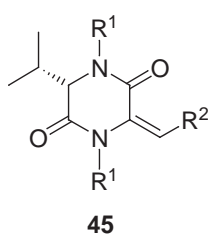

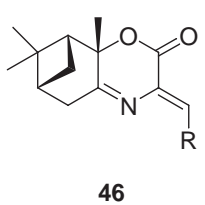

Figure 4 

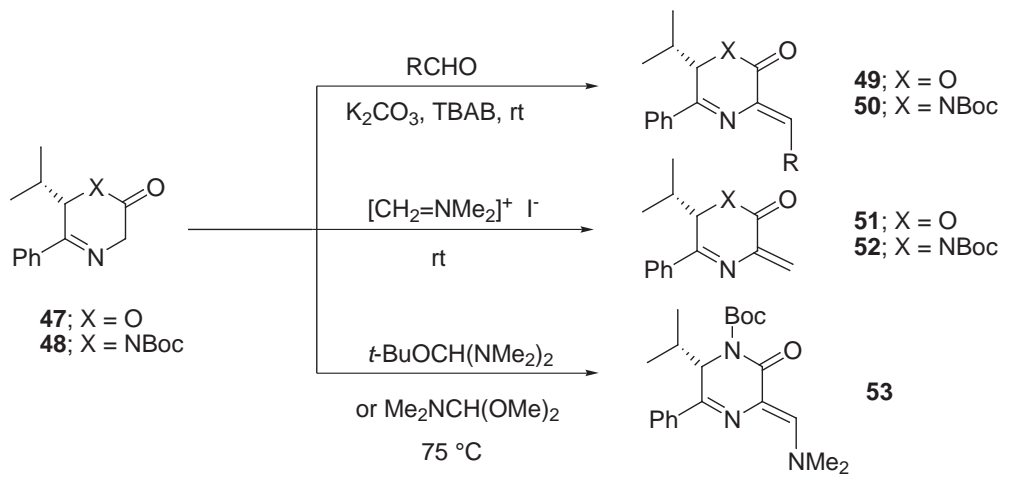

Equation 8

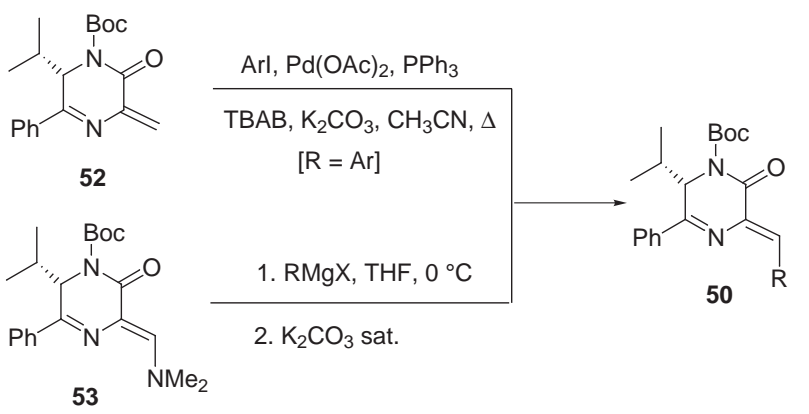

Equation 9

obtained with Pearlman's catalyst in methanol at room temperature and at normal pressure, to give all-cis-morpholin-2-ones 54 in 62-95\% yield and 92-94\% de. When the hydrogenation process was performed in the presence of aqueous formaldehyde, the corresponding $\mathrm{N}$-methylmorpholinones 55 were obtained in $70-75 \%$ yield and 82 $96 \%$ de. $^{47}$ The easy hydrogenation of the imine group is due to the conjugation of the phenyl group and occurred with total diastereoselectivity. The configuration was assigned by NMR studies as well as by X-ray diffraction analysis on product $55(\mathrm{R}=t-\mathrm{Bu})$. The hydrolysis was studied only in the case of morpholinones $\mathbf{5 5}$ in order to obtain $N$-methyl- $\alpha$-amino acids ( $N$-MAAs) because they are important components of peptides and depsipeptides isolated from plant strains, microorganisms and marine species. ${ }^{51}$ Hydrogenolytic cleavage of the benzylamine moiety in morpholinones $55(\mathrm{R}=\mathrm{Me}, i$-Pr $)$ was achieved

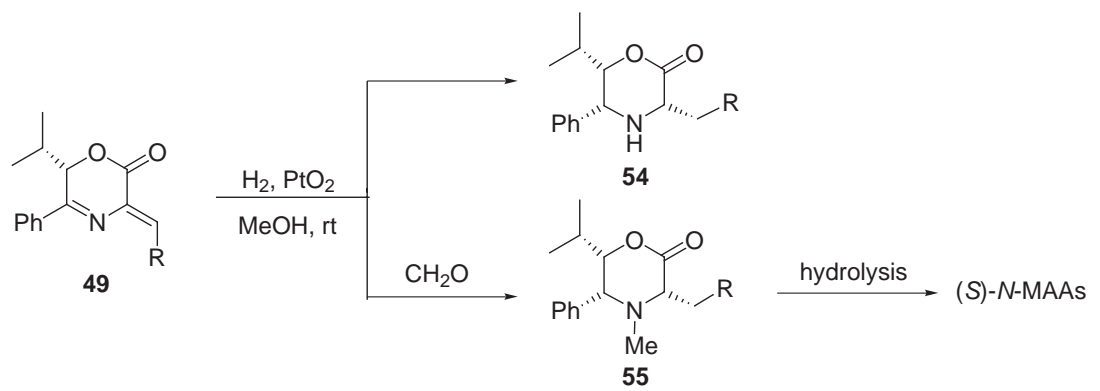

Equation 10

with Pearlman's catalyst and hydrogen at 3.5 bar in methanol in the presence of trifluoroacetic acid, followed by hydrolysis with $6 \mathrm{M}$ hydrochloric acid at $150^{\circ} \mathrm{C}$ and treatment with propylene oxide. Thus, enantiomerically pure $(S)$-2-(methylamino)butanoic acid and $(S)$ - $N$-MeLeu were isolated in $63 \%$ and $83 \%$ overall yield, respectively (Equation 10).

The diastereoselective cyclopropanation ${ }^{52}$ of DDAA derivatives 49 and 50 was achieved using Corey's dimethylsulfoxonium methylide, ${ }^{53}$ prepared in DMF or DMSO with sodium hydride as base at room temperature. This methodology was applied to the synthesis of (-)-allo-norcoronamic acid $\mathbf{5 8}$ and (-)-allo-coronamic acid 59, which play an important role in the control of enzymatic processes for plant growth and fruit ripening. The cyclopropanation was carried out using oxazinone and pyrazinone DDAA derivatives 49 and $50(\mathrm{R}=\mathrm{Me}, \mathrm{Et})$. Spirocyclic compounds 56 and 57 were obtained in 9:1 dr in the case of oxazinones ${ }^{46 a, c}$ in 11:1 dr $(\mathrm{R}=\mathrm{Me})$ and 23:1 dr $(\mathrm{R}=\mathrm{Et})$ for pyrazinones. ${ }^{47}$ Pure diastereomers could be isolated after flash chromatography in $52 \%(\mathrm{R}=\mathrm{Me})$ and $63 \%$ $(\mathrm{R}=\mathrm{Et})$ yield for oxazinones and in $70 \%(\mathrm{R}=\mathrm{Me})$ and $79 \%(\mathrm{R}=\mathrm{Et})$ yield for pyrazinones. The configuration of $56(\mathrm{R}=\mathrm{Et})$ was determined by X-ray diffraction analysis. ${ }^{46 c}$ The minor diastereomers result probably from attack at the most hindered side; alternatively, a $\beta, \gamma$-rotation of the formed enolate adduct prior to the intramolecular displacement of DMSO has to be ruled out. The corresponding 1-aminocyclopropanecarboxylic acids (ACCs) $\mathbf{5 8}$ and $\mathbf{5 9}$ were obtained from the oxazinones in $60 \%$ and 
$67 \%$ yield, respectively in enantiomerically pure form after hydrolysis with $6 \mathrm{M}$ hydrochloric acid at $150{ }^{\circ} \mathrm{C}$ and treatment of the hydrochlorides with propylene oxide in the case of oxazinones (Equation 11). However, pyrazinone derivatives $\mathbf{5 7}$ decomposed under several hydrolysis conditions, and (-)-allo-norcoronamic acid $\mathbf{5 8}$ could be isolated in $24 \%$ yield after treatment with $3 \mathrm{M}$ hydrochloric acid at $100^{\circ} \mathrm{C}$ for 4 days. ${ }^{47 \mathrm{~b}}$

The Diels-Alder cycloaddition reaction was performed with dehydroalanine derivatives $\mathbf{5 1}$ and $\mathbf{5 2}$, which behave as better dienophiles ${ }^{54}$ than other dehydroalanine related systems,${ }^{55}$ reacting with cyclic dienes under smooth reaction conditions and with endo-selectivity. endo-Adducts $\mathbf{6 0}^{46}$ and $\mathbf{6 1},{ }^{47}$ were mainly obtained using cyclopentadiene after reaction at room temperature for 3 hours and isolated after purification in 55\% and $42 \%$ yield, respectively. The configuration of adduct $\mathbf{6 0}$ was established by X-ray diffraction analysis. ${ }^{46 \mathrm{~b}}$ For cyclohexadiene it was necessary to heat at $90^{\circ} \mathrm{C}$ for 6 hours affording oxazinone $\mathbf{6 2}^{46}$ in $49 \%$ yield. In the case of pyrazinone $\mathbf{5 2}$ the reaction was carried out at room temperature for 6 days providing adduct $63^{47}$ in $95 \%$ yield, the configuration of which was determined by NMR studies on a reduced derivative of $\mathbf{6 3}^{.47 \mathrm{~b}}$ The corresponding saturated bicyclic amino acids were isolated after hydrogenationhydrolysis processes. (-)-(1R,2R,4S)-2-Aminobicyclo[2.2.1] heptane-2-carboxylic acid $\mathbf{6 4}$ was obtained in $85 \%$ and $61 \%$ yield based on oxazinone $\mathbf{6 2}$ and pyrazinone 52, respectively (Equation 12). Related bicyclo[2.2.2] octane $\mathbf{6 5}$ was isolated in $85 \%$ and $38 \%$ overall yield based on oxazinone 63 and pyrazinone 52, respectively. These type of bicyclic amino acids are very resistant to metabolic attack. Compound 64 inhibits the transport of non polar $\alpha$-amino acids across cell membranes, acts as insulin releasing factor, and inhibits fla- voprotein amino acid oxidases, whereas amino acid $\mathbf{6 5}$ perturbs selectively the levels of neutral amino acids in the cerebral cortex. ${ }^{56}$

A noticeable feature of these dienophiles $\mathbf{5 1}$ and $\mathbf{5 2}$ is their high reactivity and the endo-selectivity compared to other DDAA derivatives such as $\mathbf{4 3},{ }^{55}$ which need days to react with cyclopentadiene and gave exo-cycloadducts. The rather low energy of their LUMO ${ }^{54}$ and the lower steric hindrance close to the nitrogen atom in compounds $\mathbf{5 1}$ and 52 explain the observed difference in reactivity and stereoselectivity.

\subsection{Chiral Azomethine Ylides}

At this point we were interested in studying further applications of chiral saturated oxazinones $\mathbf{6 9}$ and 70, derived from glycine $\mathbf{4 7}$ and alanine 18 templates, respectively, as precursors of chiral azomethine ylides. Thus, the most direct strategy for the synthesis of enantiomerically enriched substituted prolines is 1,3-dipolar cycloaddition between chiral azomethine ylides stabilized by a carboxy function and a dipolarophile. Furthermore, it is possible to control the simultaneous formation of four defined stereocenters. ${ }^{196,57}$ Seebach's imidazolidinone-derived ylide 66, ${ }^{58}$ Williams' 67, ${ }^{59}$ and Harwood's morpholin-2-one ylides $\mathbf{6 8}^{60}$ have been used efficiently as chiral dipoles (Figure 5). Moreover, morpholin-2-ones 69 and 70 derived ylides $\mathbf{7 1}$ and $\mathbf{7 2}$ bearing bulky groups, such as an isopropyl at C-6 and a phenyl at C-5 could determine the diastereoselection of the cycloaddition reaction.

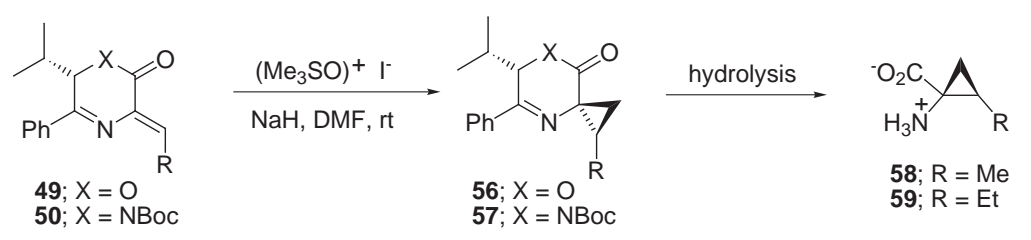

Equation 11

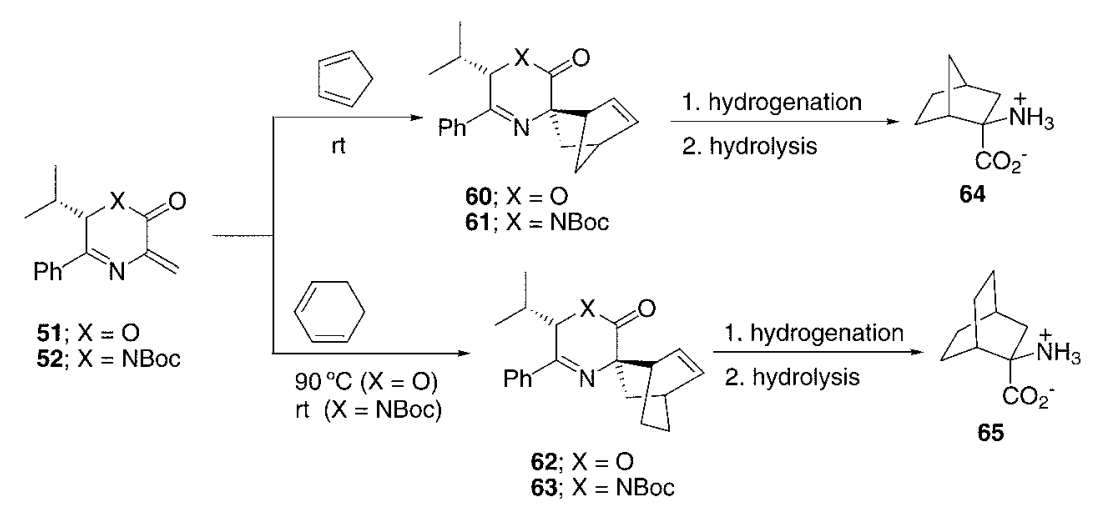

Equation 12 
<smiles>CC1C(=O)N(C)[C@@H](C(C)(C)C)N1C</smiles>

66<smiles>CC=CN1C(C)C(=O)OC(c2ccccc2)C1c1ccccc1</smiles>

67

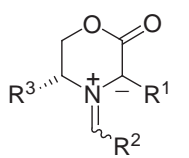

68
Figure 5

Catalytic hydrogenation of glycine 47 and alanine 18 oxazinones under normal hydrogen pressure in the presence of palladium on carbon afforded diastereoselectively morpholin-2-ones 69 and 70 in $70 \%$ and $90 \%$ yield, respectively. ${ }^{61}$ They reacted with different electron-deficient olefins or acetylenes in the presence of paraformaldehyde in toluene at $80{ }^{\circ} \mathrm{C}$ to furnish the corresponding cycloadducts 73 and 74 (22-75\% isolated yields) as major products as a consequence of a high endo-selectivity (Equation 13). This stereoselectivity is higher than that observed when using dipoles $\mathbf{6 8},{ }^{60}$ but slightly lower than employing morpholinone-derived dipoles 67. ${ }^{59}$ Theoretical studies using the PM3 hamiltonian ${ }^{62,63}$ on dipole 72 showed a more stable conformation with the phenyl and isopropyl groups in pseudo-axial and in pseudo-equatorial position, respectively. In the case of using ethyl acetylenecarboxylate, the reaction with ylid $\mathbf{7 2}$ was totally regioselective affording unsaturated product $74\left(\mathrm{R}^{1}=\mathrm{H}, \mathrm{R}^{2}=\mathrm{CO}_{2} \mathrm{Et}\right)$, according to the frontier orbital coefficients in azomethine ylides and dipolarophiles. ${ }^{57}$ The degree of asymmetric induction was fairly high corresponding to attack of the dipolarophile at the less hindered face of dipoles $\mathbf{7 1}$ and $\mathbf{7 2}$.

The X-ray diffraction analysis of adduct $\mathbf{7 4}$, derived form $\mathrm{N}$-methylmaleimide allowed the configuration of all stereocenters to be assigned. This adduct was hydrolyzed to proline $\mathbf{7 5}$ in $60 \%$ overall yield by esterification with methanol followed by hydrogenolysis at 3.5 bar with Pearlman's catalyst and hydrolysis and precipitation of the free amino acid (Equation 14).

For the transition structures, the PM3 semi-empirical method $^{62}$ and the hybrid Hartree-Fock (HF)/DTF method B3LYP/6-31G(d) ${ }^{18}$ revealed that endo and exo approaches were concerted but asynchronous, with a difference of energies of 0.7 and $2.4 \mathrm{Kcal} / \mathrm{mol}$, respectively, always favouring the former. ${ }^{61}$

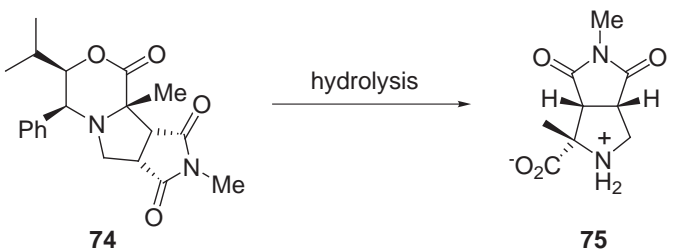

Equation 14

\section{$3 \quad$ Protecting-group Reagents}

The use of benzyloxylcarbonyl (Cbz) and 9-fluorenylmethoxycarbonyl (Fmoc) groups for temporary protection of primary and secondary amines, and specially for amino acids, was a key discovery in modern peptide chemistry. ${ }^{3}$ These carbamates as well as the tert-butoxycarbonyl (Boc) group are very useful for minimizing racemization, generally by formation of oxazolones when $\mathrm{N}$-acylated amino acids are prepared. In addition, they can be cleaved under different reaction conditions. For the introduction of the Boc group, di-tert-butyldicarbonate is the most useful reagent, while for $\mathrm{Cbz}$ and Fmoc the corresponding chloroformate esters are used. However, these chloroformates are unstable, highly toxic and have tendency to promote the formation of undesirable protected dipeptides. ${ }^{64,65}$ For these reasons other Cbz-X and Fmoc-X reagents have been developed, $N$-hydroxysuccinimide derivatives $\mathrm{Cbz}-\mathrm{OSu}$ and Fmoc-OSu being particularly useful, allow $\mathrm{N}$-protection to be performed in the absence of a base. We have been working on the preparation of reagents $\mathrm{Cbz}-\mathrm{OX} \mathbf{7 6}$ and Fmoc-OX 77 derived from $N$-hydroxysuccinimide, $N$-hydroxy-5-norbonene-2,3-dicarboxamide, $N$-hydroxyphthalimide and 1-hydroxybenzotriazole (HOBt). Our aims have been to find simple, economical, easily scalable and green processes for the preparation of reagents 76 and 77 (Figure 6). For this purpose, two aspects of the synthesis have been improved. Firstly, the in situ preparation of $N$-hydroxyimides HOX by the simple reaction of aqueous hydroxylamine with the corresponding anhydride in water as the solvent. Secondly, the reaction of these aqueous solutions with the corresponding benzyl or 9-fluorenylmethyl chloroformates under PTC conditions. ${ }^{66}$ The reaction between these

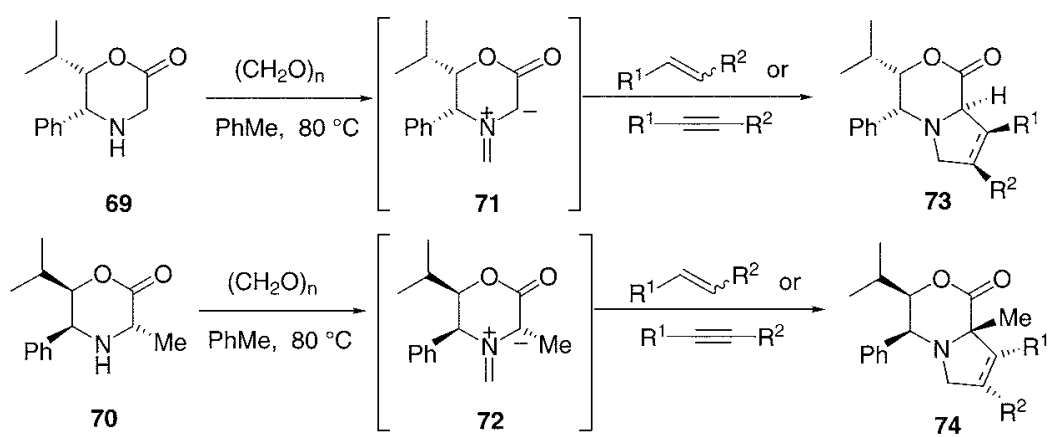

Equation 13 
<smiles>O=C(O)OCc1ccccc1</smiles>

76

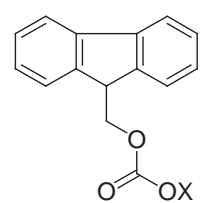

77

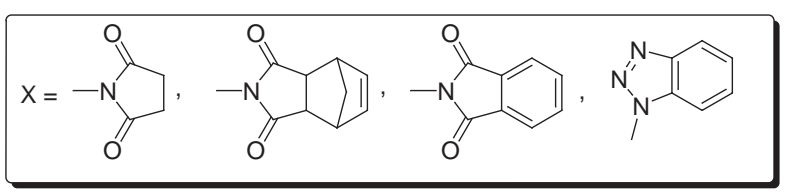

$$
\text { . }
$$

Figure 6

chloroformates and $N$-hydroxyimides or 1-hydroxybenzotriazole hydrate was carried out in a mixture of an organic solvent (toluene, dichloromethane) and water, using potassium carbonate as base and tetrabutylammonium chloride as phase-transfer catalyst. These processes have been carried out in $20 \mathrm{mmol}$ and in some cases in $3 \mathrm{~mol}$ scale and with overall yields ranging from $62 \%$ to $94 \%$.

In this context we envisaged that the development of polymer supported Cbz-OSu and Fmoc-OSu reagents would allow the easy separation and recycling of the $\mathrm{P}-\mathrm{XOH}$ reagent. Recent examples of Fmoc, $\mathrm{Cbz}$ and Boc-derivatives of a polystyrene-bound $\mathrm{HOBt}^{67}$ and of a $\mathrm{N}$ hydroxysuccinimide (HOSu) ring-opening metathesis polymer ${ }^{68}$ have been used as protecting group reagents. We focused our attention on the very inexpensive commercially available poly(styrene-alt-maleic anhydride), which, by reaction with aqueous hydroxylamine gave rise to a poly(styrene-co- $N$-hydroxymaleimide) $78(\mathrm{P}-\mathrm{HOSu})$ with an activity of $1.5 \mathrm{mmolg}^{-1}$. The acylation with benzyl or fluorenylmethyl chloroformates, as previously described for reagents 76 and 77, afforded Cbz-P-OSu 79 and Fmoc-P-OSu 80 as stable white solids soluble in polar solvents such as methanol, acetone, DMSO, and DMF (Figure 7). The protection of amines and amino acids took place with only one equivalent of these reagents in acetone-water in the presence of potassium carbonate. The corresponding products were isolated in good yields 3590\% for Cbz- and 40-95\% for Fmoc-derivatives with recovery of the P-HOSu. ${ }^{69}$ The synthesis of other P-HOSubased protecting-group reagents is underway.<smiles>CC(CC1C(=O)C(=O)N(O)C1=O)c1ccccc1</smiles><smiles>[R]COC(=O)ON1C(=O)C([Y])C2CC(CC)CC21</smiles>

$79 ; \mathrm{R}=\mathrm{Ph}$ 80; $R=9$-fluorenyl

Figure 7

\section{$4 \quad$ Peptide Coupling Reagents}

The synthesis of peptides, either in solution or in solid phase, needs the activation of the carboxylic functionality of the amino acid, usually by a peptide coupling reagent. ${ }^{4}$ The important requirements for a coupling protocol are: (a) high yields, (b) fast processes and (c) prevention of racemization. Carbodiimides in combination with HOX additives, such as those previously mentioned for the synthesis of protecting group reagents, is a classical methodology used to generate in situ active esters. Phosphonium and aminium salts as well as other reagents, have become very efficient activating agents in both solution and solid phase peptide synthesis. In this field we have considered the synthesis of new economical reagents based on carbodiimides and aminium salts.

We found out that previously mentioned polymer-supported $N$-hydroxysuccinimide (P-HOSu, 78) ${ }^{70}$ behaves as a nice recoverable additive for dicyclohexylcarbodiimide (DCC)-mediated solution-phase synthesis of simple diand tri-peptides. ${ }^{71}$ These studies have been carried out with both HOSu and P-HOSu by choosing different protected (Boc, Cbz, Fmoc) $\alpha$-amino acids at room temperature in the presence of pyridine as a base in acetonitrile for 6 to 7 hours. Yields (83-98\%) were similar for both additives, although in some cases P-HOSu was more effective than HOSu. In the case of difficult couplings, for example for $\alpha, \alpha$-dialkylamino acids such as $\alpha$-aminoisobutyric acid (Aib) or $N$-methyl- $\alpha$-amino acids, the reaction was performed at $40{ }^{\circ} \mathrm{C}$ in 1 day (yields $47-70 \%$ ). The extent of racemization was examined with Anteunis'test ${ }^{72}$ (the coupling of CbzGlyPheOH and ValOMe) affording the corresponding tripeptide in 18:1 and 24:1 diastereomeric ratios with $\mathrm{P}-\mathrm{HOSu}$ and $\mathrm{HOSu}$, respectively, whereas the dr was 9:1 without the additive. The P-HOSu could be recovered by precipitation with hexanes and simple filtration. This polymer showed good mechanical stability, the cross-linking with diamines as in the case of poly(ethylene-co- $N$-hydroxymaleimide) ${ }^{70 a, b}$ not being necessary.

Aminium salts became very popular reagents owing to their efficiency and low degree of racemization. 1-Hydroxybenzotriazole (HOBt) is the most used HOX system being the leaving group in reagents such as $O$-benzotriazol-1-yl- $N, N, N^{\prime}, N^{\prime}$-tetramethyluronium hexafluorophosphate (HBTU, 81) and tetrafluoroborate (TBTU, 82) (Figure 8$).{ }^{4}$ These reagents have an aminium structure on the solid state. After the coupling process the peptide has to be carefully washed with water in order to remove all traces of HOBt. We envisaged that the use of a polymerbound HOBt for the preparation of onium salts would facilitate the separation and recovery of the reagent. Thus, the related polymer-supported reagents P-HBTU $\mathbf{8 3}^{73}$ and P-TBTU $84^{74}$ have been prepared from the already described polystyrene-bound $\mathrm{HOBt}^{75}$ by reaction with the chlorouronium hexafluorophosphate or tetrafluoroborate derived from tetramethylurea (TMU) and oxalyl chloride, in the presence of pyridine. ${ }^{73,74}$ 
<smiles>[X]c1cccc2c1nnn2C([N+](=O)[O-])=[N+]([O-])C(On1nnc2ccccc21)=[N+]([O-])O</smiles>

81; $\mathrm{X}=\mathrm{PF}_{6}(\mathrm{HBTU})$ $82 ; \mathrm{X}=\mathrm{BF}_{4}(\mathrm{TBTU})$

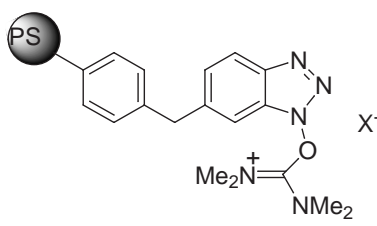

83; $\mathrm{X}=\mathrm{PF}_{6}(\mathrm{P}-\mathrm{HBTU})$ 84; $\mathrm{X}=\mathrm{BF}_{4}(\mathrm{P}-\mathrm{TBTU})$
Figure 8

P-TBTU 84 was assayed in di- and tri-peptide synthesis and compared with TBTU 82. ${ }^{74}$ The experiments were carried out in acetonitrile as solvent and pyridine as base for 1 day at room temperature or at $50{ }^{\circ} \mathrm{C}$ in the case of hindered amino acids (Aib and $N$-MeVal). In general, the reaction times were longer with the polymeric reagent and yields slightly lower. No racemization was detected when the Anteunis' test ${ }^{72}$ was performed. P-TBTU was found to be effective even under aqueous conditions. Thus, the coupling in acetonitrile containing 5\% water took place with the same yield as in neat acetonitrile. Polymer-supported P-HOBt was recovered by simple filtration and reused again for the preparation of P-TBTU. Similar results have been found with P-HBTU. ${ }^{73}$

Our aims in the case of non-supported peptide coupling reagents, were: (a) to find an inexpensive water soluble $\mathrm{XOH}$ leaving group, (b) to use a one-pot phosgene-free procedure for the synthesis of aminium salts in order to facilitate its scale-up, and (c) to use non-toxic ureas. As an alternative to already described HOX systems, we focused our attention on the economically favourable 2-mercaptopyridine-1-oxide $\mathbf{8 5}$, which is also very soluble in water and can be easily removed by extractive workup. The corresponding TMU-derived thiouronium reagents $(S)$-(1-oxido-2-pyridinyl)-1,1,3,3-tetramethylthiouronium hexafluorophosphate $\mathbf{8 7}, \mathrm{HOTT}^{76}$ and tetrafluoroborate 88, TOTT were prepared in 55\% and $75 \%$ overall yield following a one-pot procedure by reaction with the chlorouronium salts in the presence of triethylamine (Equation 15). ${ }^{77}$ For the synthesis of chlorouronium salts 86 a phosgene-free protocol based on the use of oxalyl chloride and a catalytic amount of DMF, followed by in situ anion interchange was used.

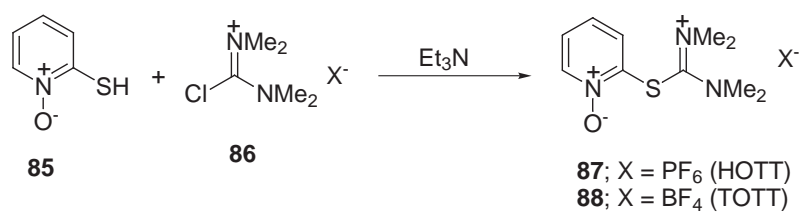

\section{Equation 15}

Reagents 87 and 88 were used in the solution-phase synthesis of peptides and compared with other coupling reagents, such as TBTU 82. In general, good yields (71$97 \%$ ) were obtained in acetonitrile or DMF with triethy- lamine as base even coupling Aib and $N$-MeAAs (35$82 \%$ yields). Anteunis' test ${ }^{72}$ gave 10:1 dr and Young's test (synthesis of BzLeu-Gly-OEt) ${ }^{78}$ afforded $7 \%$ and $3.7 \%$ racemization with HOTT 87 and TOTT 88 , respectively. These values are lower when compared to other HOBt-based uronium salts, for example HBTU 81 gave $12.7 \%$ racemization in Young's test. ${ }^{79}$

In order to check the efficiency of HOTT 87 and TOTT 88 in solid-phase peptide synthesis (SPPS), the manual stepwise solid-phase assembly of a pentapeptide related to Leu-enkephalinamide, H-Tyr-Aib-Aib-Phe-LeuNH ${ }_{2},{ }^{80}$ in which Gly has been substituted by Aib, was performed following a Fmoc/t-Bu protection scheme. A poly(ethyleneglycol)-polystyrene (PEG-PS)-resin bearing a peptide amide Rink linker was used as solid support, in DMF as solvent, diisopropylethylamine (DIEA) as base and TBTU 82 as coupling reagent except for the Aib-Aib bond. After 2 hours reaction with HOTT and TOTT, 24\% and $19 \%$ yield of pentapeptide was obtained, similar to TBTU, which gave $29 \%$ of efficiency. ${ }^{81}$ The extent of racemization in SPPS was studied with two model tripeptides containing Ser (H-Gly-Ser-Phe- $\left.\mathrm{NH}_{2}\right)^{82}$ and His $(\mathrm{H}-$ Gly-His-Phe- $\left.\mathrm{NH}_{2}\right),{ }^{83}$ which are especially prone to racemization. The synthesis was performed following the same methodology described above for efficiency studies using HOTT, TOTT and TBTU and we observed in all cases $<1 \%$ of racemization for the Ser-model and $1.6 \%$, $1.4 \%$ and $2.9 \%$, respectively for the His-model. ${ }^{81}$

These thiouronium salts $\mathbf{8 7}$ and $\mathbf{8 8}$ have also been used as amidation reagents for the synthesis of amides (45-95\% yield) derived from aliphatic and aromatic acids $\mathbf{8 9}$ and different substituted amines. ${ }^{77}$ Moreover, starting from carboxylic acids, primary amides 90 can be easily prepared by reaction with ammonium chloride in DMF as solvent and DIEA as base. ${ }^{84}$ The reaction is very fast (30 min) and takes place at room temperature even with hindered substrates. Different functionalised carboxylic acids and protected (Boc, $\mathrm{Cbz}$ and Fmoc) $\alpha$-amino acids have been transformed successfully into the corresponding pure amides (46-99\% yield). ${ }^{84}$ These reagents are also very effective for the synthesis of hydroxamates such as Weinreb amides 91, and $O$-methyl or $O$-benzylhydroxamates 92 under similar reaction conditions (2-3 h, r.t.) described for primary amides (Equation 16). Different carboxylic acids $\mathbf{8 9}$, as well as protected $\alpha$-amino acids, were transformed into pure hydroxamates 91 and 92 in high yields (70-95\%) without appreciable racemization. ${ }^{85}$

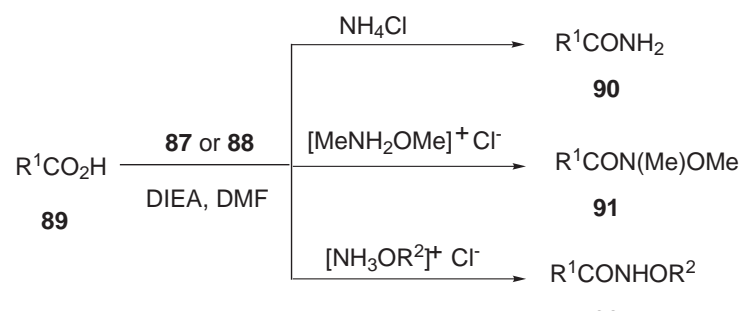

92

Equation 16 
Taking into account the reported embryotoxicity of tetramethylurea (TMU), ${ }^{86}$ we have prepared the analogous thiouronium salts 94 (HODT) and 95 (TODT) derived from a non toxic urea, the common solvent 1,3-dimethylpropyleneurea (DMPU). ${ }^{81}$ They have been synthesised following the same one-pot phosgene free methodology described for HOTT and TOTT. The chlorouronium 93 as well as the thiouronium salts 94 and 95 are more stable than the corresponding 1,3-dimethylethyleneurea derivatives. ${ }^{87}$ We have studied the use of these reagents 94 (HODT) and 95 (TODT) in solution and in solid-phase peptide synthesis, being as efficient as $\mathbf{8 7}$ (HOTT) and $\mathbf{8 8}$ (TOTT) in solution. However, higher degrees of racemization were obtained with DMPU reagents in the Young's test ${ }^{78}$ (39.7\% and $41.1 \%$, respectively), whereas Anteunis' test $^{72}$ gave similar results $(7.4 \%$ and $9.0 \%$, respectively). ${ }^{81}$ For the SPPS, a lower yield in the synthesis of Leu-enkephalinamide system (10\% and 14\%) and similar racemization ratios (Ser: $<1 \%$ and His: $2.0 \%$ ) were observed. ${ }^{81}$

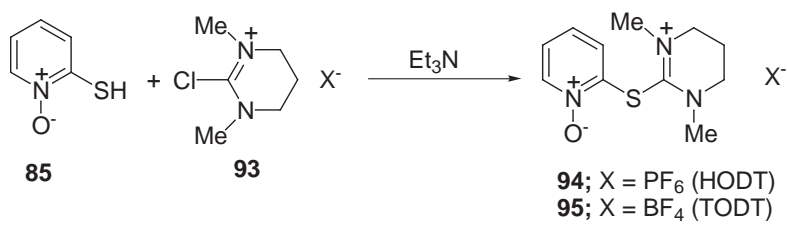

Equation 17

\section{5}

\section{Conclusion}

This account has shown that chiral acyclic glycine imines derived from ephedrine-imidazolidinones and from pseudoephedrine are appropriate templates for the asymmetric synthesis of monoalkylated cyclic and acyclic $\alpha$-amino acids by means of diastereoselective alkylation reaction under mild easily scalable reaction conditions. However, the cyclic chiral alanine imines either with oxazinone or pyrazinone structures are more convenient templates for the synthesis of dialkylated $\alpha$-amino acids. For the enantioselective alkylation of acyclic imino glycinates, polymer-supported Cinchona alkaloid-derived ammonium salts are recyclable phase-transfer catalysts, whereas for imino alaninates, bis(aminomethyl)binaphthols (BINOLAMs) are the appropriate phase-transfer catalysts. Chiral $\alpha, \beta$-didehydroamino acid derivatives with oxazinone and pyrazinone structure have been used successfully in hydrogenation, Heck, cyclopropanation and Diels-Alder reactions for the asymmetric synthesis of NMAAs, ACCs and bicyclic amino acids. Azomethine ylides derived from the morpholinones, prepared by hydrogenation of oxazinones, are excellent dipoles for the 1,3-dipolar cycloaddition with dipolarophiles for the asymmetric synthesis of prolines. In the field of protection of amino acids, Fmoc-P-OSu and Cbz-P-OSu, derived from polymeric $N$-hydroxysuccinimide (P-HOSu) are very effective reagents for the protection of amino groups.
In the case of peptide coupling reagents, polymeric $\mathrm{P}$ HOSu/DCC and P-TBTU and P-HBTU are very efficient for solution-phase synthesis whereas thiouronium salts derived from 2-mercaptopyridine-1-oxide and TMU, such as HOTT and TOTT, and from DMPU, such as HODT and TODT have been used in solution- and solid-phase peptide synthesis with efficiency and racemization rates comparable to other aminium salts. They can also be used for the direct preparation of primary amides, Weinreb amides and other hydroxamates by direct coupling of carboxylic acids and amino acids with ammonium chloride or hydroxylamine derivatives.

\section{Acknowledgement}

First of all I want to thank all my co-workers whose names appear in the references for their fundamental, both experimental and intellectual, contribution to the chemistry described in this account. Continuous financial support by the national and regional administrations through the corresponding institutions (Ministerio de Educación y Ciencia, Ministerio de Ciencia y Tecnología and Generalitat Valenciana) is gratefully acknowledged. I also thank Luxembourg Industries (PAMOL) Ltd. and ASAC Pharmaceuticals International S. A. for generous financial support.

\section{References}

(1) (a) Amino Acids Peptides and Proteins, Vol. 1-28; Specialist Periodical Reports Chem. Soc.: London, 1968-1995.

(b) Wipf, P. Chem. Rev. 1995, 95, 2115. (c) Humphrey, J. M.; Chamberlin, A. R. Chem. Rev. 1997, 97, 2243.

(d) Fletcher, M. D.; Campbell, M. M. Chem. Rev. 1998, 98, 763. (e) Andrews, M. J. I.; Tabor, A. B. Tetrahedron 1999, 55, 11711. (f) Albericio, F.; Kates, S. A. In Solid-Phase Synthesis, A Practical Guide; Kates, S. A.; Albericio, F., Eds.; Marcel Dekker: New York, 2000, 275.

(2) (a) Coppola, G. M.; Schuster, H. F. Asymmetric SynthesisConstruction of Chiral Molecules Using Amino Acids; John Wiley and Sons: New York, 1987. (b) Williams, R. M. Synthesis of Optically Active Amino Acids; Pergamon Press: Oxford, 1989. (c) Heimgartner, H. Angew. Chem., Int. Ed. Engl. 1991, 30, 238. (d) Cintas, P. Tetrahedron 1991, 47, 6079. (e) Williams, R. M.; Hendrix, J. A. Chem. Rev. 1992, 92, 889. (f) Duthaler, R. O. Tetrahedron 1994, 50, 1540. (g) Bailey, P. D.; Clayson, J.; Boa, A. N. Contemp. Org. Synth. 1995, 2, 173. (h) North, M. Contemp. Org. Synth. 1996, 3, 323. (i) Studer, A. Synthesis 1996, 793.

(j) Seebach, D.; Sting, A. R.; Hoffmann, M. Angew. Chem., Int. Ed. Engl. 1996, 35, 2709. (k) Cativiela, C.; Díaz-deVillegas, M. D. Tetrahedron: Asymmetry 1998, 9, 3517. (1) Cativiela, C.; Díaz-de-Villegas, M. D. Tetrahedron: Asymmetry 2000, 11, 645.

(3) (a) Kocienski, P. J. Protecting Groups; Thieme Verlag: Stuttgart, 1994. (b) Greene, T. W.; Wuts, P. G. M. Protective Groups in Organic Synthesis, 3rd Ed.; John Wiley and Sons: New York, 1999. (c) Jaro, K. Contemp. Org. Synth. 1995, 2 , 315. (d) Jaro, K. Contemp. Org. Synth. 1996, 3, 397. (e) Jaro, K. Contemp. Org. Synth. 1997, 4, 454.

(f) Schelhaas, M.; Waldmann, H. Angew. Chem., Int. Ed. Engl. 1996, 35, 2056. (g) Jarowicki, K.; Kocienski, P. J. J. Chem. Soc., Perkin Trans. 1 1998, 4005. (h) Jaro, K. J. Chem. Soc., Perkin Trans. 1 1999, 1589. (i) Jaro, K. J. Chem. Soc., Perkin Trans. 1 2000, 2495. (j) Theodoridis, G. Tetrahedron 2000, 56, 2339. 
(4) (a) Albericio, F.; Carpino, L. A. Methods Enzymol. 1997, 289, 104. (b) Albericio, F.; Chinchilla, R.; Dodsworth, D. J.; Nájera, C. Org. Prep. Proced. Int. 2001, 33, 203.

(5) For a review about imines for the synthesis of $\alpha$-amino acids see: Abellán, T.; Chinchilla, R.; Galindo, N.; Guillena, G.; Nájera, C.; Sansano, J. M. Eur. J. Org. Chem. 2000, 2689.

(6) O'Donnell, M. J.; Bennett, W. D.; Bruder, W. A.; Jacobsen, W. N.; Knuth, K.; LeClef, B.; Polt, R. L.; Bordwell, F. G.; Mrozack, S. R.; Cripe, T. A. J. Am. Chem. Soc. 1988, 110, 8520.

(7) O'Donnell, M. J.; Esikova, I. A.; Mi, A.; Shullenberger, D. F.; Wu, S. In Phase-Transfer Catalysis, ACS Symposium Series 659, Chap. 10; Halpern, M. E., Ed.; ACS: Washington D.C., 1997.

(8) Genet, J.-P.; Juge, S.; Achi, S.; Mallart, S.; Ruíz Montes, J.; Levif, G. Tetrahedron 1988, 44, 5263.

(9) For recent uses of this auxiliary in asymmetric synthesis see for instance: (a) Orena, M.; Porzi, G.; Sandri, S. Tetrahedron Lett. 1992, 33, 3797. (b) Jenssen, K. N.; Roos, G. H. P. Tetrahedron: Asymmetry 1992, 3, 1553.

(c) Melnyk, O.; Stephan, E.; Pourcelot, G.; Cresson, P. Tetrahedron 1992, 48, 841. (d) Drewes, S. E.; Malissar, D. G. S.; Roos, G. H. P. Chem. Ber. 1993, 126, 2663. (e) Anand, R. C.; Singh, V. Tetrahedron 1993, 49, 6515. (f) Cardillo, G.; De Simone, A.; Gentilucci, L.; Sabatino, P.; Tomasini, C. Tetrahedron Lett. 1994, 35, 5051. (g) Van Heerden, P. S.; Bezuidenhoudt, B. C. B.; Ferreira, D. Tetrahedron Lett. 1997, 38, 1821. (h) Bongini, A.; Cardillo, G.; Gentilucci, L.; Tomasini, C. J. Org. Chem. 1997, 62, 9148. (i) Trost, B. M.; Ceschi, M. A.; König, B. Angew. Chem., Int. Ed. Engl. 1997, 36, 1486. (j) Caddick, S.; Jenkins, K.; Treweeke, N.; Candeias, S. X.; Afonso, C. A. M. Tetrahedron Lett. 1998, 39, 2203. (k) Roos, G. H. P.; Balasubramaniam, S. Synth. Commun. 1998, 28, 3877. (1) Versttg, M.; Bezmidenhoudt, B. C. B.; Ferreira, D. Tetrahedron 1999, 55, 3365. (m) Cardillo, G.; Gentilucci, L.; Tolomelli, A. Tetrahedron Lett. 1999, 40, 8261.

(10) (a) Guillena, G.; Nájera, C. Tetrahedron: Asymmetry 1998, 9, 1125. (b) Guillena, G.; Nájera, C. Tetrahedron: Asymmetry 1998, 9, 3935. (c) Guillena, G.; Nájera, C. J. Org. Chem. 2000, 65, 7310.

(11) Oppolzer, W.; Moretti, R.; Zhou, C. Helv. Chim. Acta 1994, 77, 2363.

(12) Kanai, M.; Muraoka, A.; Tanaka, T.; Sawada, M.; Ikota, N.; Tomioka, K. Tetrahedron 1995, 51, 9349.

(13) Seebach, D.; Beck, A. K.; Studer, A. In Modern Synthetic Methods; VCH: Basel, 1995, 1-178.

(14) Schwesinger, R.; Willaredt, J.; Schlemper, H.; Keller, M.; Schmitt, D.; Fritz, H. Chem. Ber. 1994, 127, 2435.

(15) (a) Myers, A. G.; Yang, B. H.; Chen, H.; Gleason, J. L. J. Am. Chem. Soc. 1994, 116, 9361. (b) Myers, A. G.; Yoon, T.; Gleason, J. L. Tetrahedron Lett. 1995, 36, 4555. (c) Myers, A. G.; Gleason, J. L.; Yoon, T. J. Am. Chem. Soc. 1995, 117, 8488. (d) Myers, A. G.; Gleason, J. L.; Yoon, T.; Kung, D. W. J. Am. Chem. Soc. 1997, 119, 656. (e) Smith, A. B. III.; Benowitz, A. B.; Favor, D. A.; Sprengeler, P. A.; Hirsmann, R. Tetrahedron Lett. 1997, 38, 3809. (f) Myers, A. G.; Gleason, J. L. Org. Synth. 1998, 76, 57.

(16) Guillena, G.; Nájera, C. Tetrahedron: Asymmetry 2001, 12, 181.

(17) Chinchilla, R. unpublished results.

(18) Frisch, M. J.; Trucks, G. W.; Schlegel, H. B.; Scuseria, G. E.; Robb, M. A.; Cheeseman, J. R.; Zakrzewski, V. G.; Montgomery, J. A. Jr.; Stratmann, R. E.; Burant, J. C.; Dapprich, S.; Millam, J. M.; Daniels, A. D.; Kudin, K. N.; Strain, M. C.; Farkas, O.; Tomasi, J.; Barone, V.; Cossi, M.; Cammi, R.; Mennucci, B.; Pomelli, C.; Adamo, C.; Clifford,
S.; Ochterski, J.; Petersson, G. A.; Ayala, P. Y.; Cui, Q.; Morokuma, K.; Malick, D. K.; Rabuck, A. D.;

Raghavachari, K.; Foresman, J. B.; Cioslowski, J.; Ortiz, J. V.; Baboul, A. G.; Stefanov, B. B.; Liu, G.; Liashenko, A.; Piskorz, P.; Komaromi, I.; Gomperts, R.; Martin, R. L.; Fox, D. J.; Keith, T.; Al-Laham, M. A.; Peng, C. Y.;

Nanayakkara, A.; Challacombe, M.; Gill, P. M. W.; Johnson, B.; Chen, W.; Wong, M. W.; Andres, J. L.; González, C.; Head-Gordon, M.; Replogle, E. S.; Pople, J. A. Gaussian 98, Revision A.9; Gaussian Inc.: Pittsburgh PA, 1998.

(19) (a) Abellán, T.; Chinchilla, R.; Galindo, N.; Nájera, C.; Sansano, J. M. J. Heterocycl. Chem. 2000, 37, 467. (b) Abellán, T.; Chinchilla, R.; Galindo, N.; Guillena, G.; Nájera, C.; Sansano, J. M. In Targets in Heterocyclic Systems, Vol. 4; Attanasi, O. A.; Spinelli, D., Eds.; SCI: Roma, 2000, 57-103.

(20) (a) Caplar, V.; Lisini, A.; Kajfez, F.; Kolbah, D.; Sunjic, V. J. Org. Chem. 1978, 43, 1355. (b) Schulz, G.; Steglich, W. Chem. Ber. 1977, 110, 3615.

(21) (a) Chinchilla, R.; Falvello, L. R.; Galindo, N.; Nájera, C. Angew. Chem., Int. Ed. Engl. 1997, 36, 995. (b) Chinchilla, R.; Galindo, N.; Nájera, C. Tetrahedron: Asymmetry 1998, 9, 2769. (c) Chinchilla, R.; Galindo, N.; Nájera, C. Synthesis 1999, 704 .

(22) The only example described for the synthesis of this kind of heterocycles is the case of 1,2,3,6-tetrahydro-6,6-dimethyl5-phenyl-2-pyrazinone prepared by reaction of 2,2dimethyl-3-phenyl-2H-azirine with glycine ethyl ester: Alvernhe, G.; Laurent, A.; Masroua, A. Tetrahedron Lett. 1983, 24, 1153.

(23) (a) Abellán, T.; Nájera, C.; Sansano, J. M. Tetrahedron: Asymmetry 1999, 9, 2769. (b) Abellán, T.; Nájera, C.; Sansano, J. M. Eur. J. Org. Chem. 2000, 2809.

(24) Voigt, K.; Stolle, A.; Salaün, J.; de Meijere, A. Synlett 1995, 226.

(25) Guillena, G. private communication.

(26) Highlights of the chemistry of AMAAs see: Wirth, T. Angew. Chem., Int. Ed. Engl. 1997, 36, 225.

(27) (a) O'Donnell, M. J. Aldrichimica Acta 2001, 34, 3. (b) Dolling, U.-H.; Davis, P.; Grabowski, E. J. J. J. Am. Chem. Soc. 1984, 106, 446.

(28) (a) Corey, E. J.; Xu, F.; Noe, M. C. J. Am. Chem. Soc. 1997, 119, 12414. (b) Corey, E. J.; Noe, M. C.; Xu, F. Tetrahedron Lett. 1998, 39, 5347. (c) Corey, E. J.; Bo, Y.; BuschPetersen, J. J. Am. Chem. Soc. 1998, 120, 13000.

(29) (a) Lygo, B.; Wainwright, P. G. Tetrahedron Lett. 1997, 38 , 8595. (b) Lygo, B.; Crosby, J.; Peterson, J. A. Tetrahedron Lett. 1999, 40, 1385. (c) Lygo, B. Tetrahedron Lett. 1999, 40, 1389. (d) Lygo, B.; Crosby, J.; Peterson, J. A. Tetrahedron Lett. 1999, 40, 8671. (e) Lygo, B.; Crosby, J.; Lowdon, T. R.; Wainwright, P. G. Tetrahedron 2001, 57, 2391. (f) Lygo, B.; Crosby, J.; Lowdon, T. R.; Peterson, J. A.; Wainwright, P. G. Tetrahedron 2001, 57, 2403.

(30) (a) Ooi, T.; Kameda, K.; Maruoka, K. J. Am. Chem. Soc. 1999, 121, 6519. (b) Ooi, T.; Takeuchi, M.; Kameda, K.; Maruoka, K. J. Am. Chem. Soc. 2000, 122, 5228. (c) Ooi, T.; Kameda, K.; Tannai, H.; Maruoka, K. Tetrahedron Lett. 2000, 41, 8339 .

(31) For a recent review about the use of TADDOLs as chiral auxiliaries see: Seebach, D.; Beck, A. K.; Heckel, A. Angew. Chem. Int. Ed. 2001, 40, 93.

(32) (a) Belokon', Y. N.; Kochetkov, K. A.; Churkina, T. D.; Ikonnikov, N. S.; Chesnokov, A. A.; Larionov, O. V.; Singh, I.; Parnar, V. S.; Kumar, R.; Kagan, H. B. Tetrahedron: Asymmetry 1999, 9, 851. (b) Belokon', Y. N.; Kochetkov, K. A.; Churkina, T. D.; Ikonnikov, N. S.; Chesnokov, A. A.; 
Larionov, O. V.; Singh, I.; Parnar, V. S.; Vyskocil, S.; Kagan, H. B. J. Org. Chem. 2000, 65, 7041.

(33) (a) Belokon', Y. N.; North, M.; Kublitski, V. S.; Ikonnikov, N. S.; Krasik, P. E.; Maleev, V. L. Tetrahedron Lett. 1999, 40, 6105. (b) Belokon', Y. N.; Davies, R. G.; North, M. Tetrahedron Lett. 2000, 41, 7245.

(34) Belokon', Y. N.; Kochetkov, K. A.; Churkina, T. D.; Ikonnikov, N. S.; Larionov, O. V.; Harutyunyan, S. R.; Vyskocil, S.; North, M.; Kagan, H. B. Angew. Chem. Int. Ed. 2001, 40, 1948.

(35) Nelson, A. Angew. Chem. Int. Ed. 1999, 38, 1583.

(36) For recent publications on this matter see: (a) Okino, T.; Takemoto, Y. Org. Lett. 2001, 3, 1515. (b) Park, H.; Jeong, B.; Yoo, M.; Park, M.; Huh, H.; Jew, S. Tetrahedron Lett. 2001, 42, 4645.

(37) (a) Kobayashi, N.; Iwai, K. J. Am. Chem. Soc. 1978, 100, 7021. (b) Inagaki, M.; Hiratane, J.; Yamamoto, Y.; Oda, J. Bull. Chem. Soc. Jpn. 1987, 60, 4121. (c) Sera, A.; Takagi, K.; Katayama, H.; Yamada, H.; Matsumoto, K. J. Org. Chem. 1988, 53, 1157. (d) Hodge, P.; Khoshdel, E.; Waterhouse, J. J. Chem. Soc., Perkin Trans. 1 1983, 2205. (e) Hodge, P.; Khoshdel, E.; Waterhouse, J.; Fréchet, J. M. J. Chem. Soc., Perkin Trans. 1 1985, 2327. (f) Hermann, K.; Wynberg, H. Helv. Chim. Acta 1977, 60, 2208. (g) Alvarez, R.; Hourdin, M.-A.; Cavé, C.; d'Angelo, J.; Chaminade, P. Tetrahedron Lett. 1999, 40, 7091. (h) Nandanan, E.; Sudalai, A.; Ravindranathan, T. Tetrahedron Lett. 1997, 38, 2577. (i) Canali, L.; Song, E. S.; Sherrington, D. C. Tetrahedron: Asymmetry 1998, 9, 1029. (j) Han, H.; Janda, K. D. J. Am. Chem. Soc. 1996, 118, 7632. (k) Han, H.; Janda, K. D. Tetrahedron Lett. 1997, 38, 1527. (1) Song, C. E.; Oh, C. R.; Lee, S. W.; Canali, L.; Sherrington, D. C. Chem. Commun. 1998, 2435. (m) Zhang, Z.; Wang, Y.; Zhen, W.; Hodge, P. React. Funct. Polym. 1999, 41, 37.

(38) Polystyrene crosslinked with $1 \%$ divinylbenzene $200-400$ mesh $17 \mathrm{mmol} / \mathrm{g}$.

(39) Chinchilla, R.; Mazón, P.; Nájera, C. Tetrahedron: Asymmetry 2000, 11, 3277.

(40) (a) Feringa, B.; Wynberg, H. Tetrahedron Lett. 1977, 4447. (b) Brussee, J.; Groenendijk, J. L. G.; Koppele, J. M.; Jansen, A. C. A. Tetrahedron 1985, 41, 3313.

(41) Cram, D. J.; Helgeson, R. C.; Peacock, S. C.; Kaplan, L. J.; Domeier, L. A.; Moreau, P.; Koga, K.; Mayer, J. M.; Chao, Y.; Siegel, M. G.; Hoffman, D. H.; Sogah, G. D. Y. J. Org. Chem. 1978, 43, 1930.

(42) Casas, J.; Nájera, C.; Sansano, J. M.; Gonzalez, J.; Saá, J. M.; Vega, M. Tetrahedron: Asymmetry 2001, 12, 699.

(43) Schmidt, U.; Lieberknecht, A.; Wild, J. Synthesis 1988, 159.

(44) Williams, R. M. Synthesis of Optically Active Amino Acids; Chap. 6, Pergamon Press: Oxford, 1989.

(45) (a) Stammer, C. H. Tetrahedron 1990, 46, 2231. (b) Burgess, K.; Ho, K.-K.; Mye-Sherman, D. Synlett 1994, 575.

(46) (a) Chinchilla, R.; Falvello, L. R.; Galindo, N.; Nájera, C. Tetrahedron: Asymmetry 1998, 9, 2223. (b) Chinchilla, R.; Falvello, L. R.; Galindo, N.; Nájera, C. Tetrahedron: Asymmetry 1999, 10, 821. (c) Chinchilla, R.; Falvello, L. R.; Galindo, N.; Nájera, C. J. Org. Chem. 2000, 65, 3034.

(47) (a) Abellán, T.; Nájera, C.; Sansano, J. M. Tetrahedron: Asymmetry 2000, 11, 1051. (b) Abellán, T.; Mancheño, B.; Nájera, C.; Sansano, J. M. Tetrahedron 2001, 57, 6627.

(48) (a) Jeffery, T. Tetrahedron 1996, 52, 10113. (b) Jeffery, T.; David, M. Tetrahedron Lett. 1998, 39, 5751.

(49) For a recent review about acylvinyl synthons see: Chinchilla, R.; Nájera, C. Chem. Rev. 2000, 100, 1891.
(50) For a review about Barbier reaction conditions see: Alonso, F.; Yus, M. Recent Res. Devel. Org. Chem. 1997, 1, 397.

(51) Spengler, J.; Burger, K. Synthesis 1998, 67; and references cited therein.

(52) For a review about asymmetric ylide reactions see: Li, A.H.; Dai, L.-X.; Aggarwal, V. K. Chem. Rev. 1997, 97, 2341.

(53) Corey, E. J.; Chaykovsky, M. J. Am. Chem. Soc. 1965, 87, 1353.

(54) PM3 calculations (Hyperchem 50 from Hypercube Inc.) gave the following frontier obital energies for oxazinone $\mathbf{5 1}$ : $\mathrm{E}_{\text {НОМо }}=-946 \mathrm{eV} \mathrm{E}_{\mathrm{LUMO}}=094 \mathrm{eV}^{46 \mathrm{c}}$ and for pyrazinone $\mathbf{5 2}$ : $\mathrm{E}_{\text {HOMO }}=-941 \mathrm{eV} \mathrm{E}_{\mathrm{LUMO}}=-108 \mathrm{eV} \cdot 47 \mathrm{~b}$

(55) Oxazolidinone dehydroalanine derivative $\mathbf{4 3}$ gave exodiastereoselectivity after $14 \mathrm{~d}$ at r.t. with cyclopentadiene and $3 \mathrm{~d}$ at $140{ }^{\circ} \mathrm{C}$ with cyclohexadiene: Pyne, S. G.; Dikic, B.; Gordon, P. A.; Skelton, B. W.; White, A. H. J. Chem. Soc., Chem. Commun. 1991, 1505.

(56) (a) Tager, H.; Christensen, H. N. J. Am. Chem. Soc. 1972, 94, 968. (b) Zand, R.; Sellinger, O. Z.; Water, R.; Harris, R. J. Neurochem. 1974, 23, 1201.

(57) Gothelf, K. V.; Jorgensen, K. A. Chem. Rev. 1998, 98, 863.

(58) Peyronel, J. F.; Grisoni, S.; Carboni, B.; Courgeon, T.; Carrié, R. Tetrahedron 1994, 50, 189.

(59) (a) Williams, R. M.; Zhai, W.; Aldons, D. J.; Aldons, S. C. J. Org. Chem. 1992, 57, 6527. (b) Sebahar, P. R.; Williams, R. M. J. Am. Chem. Soc. 2000, 122, 5666.

(60) (a) Anslow, A. S.; Harwood, L. M.; Phillips, H.; Watkin, D. Tetrahedron: Asymmetry 1991, 2, 169. (b) Anslow, A. S.; Harwood, L. M.; Phillips, H.; Watkin, D. Tetrahedron: Asymmetry 1991, 2, 997. (c) Anslow, A. S.; Harwood, L. M.; Phillips, H.; Watkin, D.; Wong, L. F. Tetrahedron: Asymmetry 1991, 2, 1343. (d) Harwood, L. M.; Lilley, I. A. Tetrahedron Lett. 1993, 34, 537. (e) Harwood, L. M.; Manage, A. C.; Robin, S.; Hopes, S. F. G.; Watkin, D.; Williams, C. E. Synlett 1993, 777. (f) Harwood, L. M.; Kitchen, L. C. Tetrahedron Lett. 1993, 34, 6603. (g) Baldwin, J. E.; McKenzie, T.; Moloney, M. G. Synlett 1994, 925. (h) Anslow, A. S.; Cox, G. G.; Harwood, L. M. Chem. Heterocycl. Compd. 1995, 31, 1222. (i) Anslow, A. S.; Harwood, L. M.; Lilley, I. A. Tetrahedron: Asymmetry 1995, 6, 2465. (j) Harwood, L. M.; Lilley, I. A. Tetrahedron: Asymmetry 1995, 6, 1557. (k) Alker, D.; Harwood, L. M.; Williams, C. E. Tetrahedron 1997, 53, 12671. (1) Harwood, L. M.; Robertson, S. M. Chem. Commun. 1998, 2641.

(61) Chinchilla, R.; Falvello, L. R.; Galindo, N.; Nájera, C. Eur. J. Org. Chem. 2001, 3133.

(62) Stewart, J. J. P. J. Comput. Chem. 1989, 10, 209.

(63) MOPAC: CS Chem3D 45, CambridgeSoft Corporation.

(64) Paquet, A. Can. J. Chem. 1982, 60, 976.

(65) Lapatsanis, L.; Milias, G.; Froussios, K.; Kolovos, M. Synthesis 1983, 671.

(66) Chinchilla, R.; Dodsworth, D. J.; Nájera, C.; Yus, M. ES P 802134, 1998.

(67) A big excess of these reagents has to be used: Dendrinos, K. G.; Kalivretenos, A. G. J. Chem. Soc., Perkin Trans. 1 1988, 1463.

(68) The preparation of this reagent requires a O-silylationpolymerization (ROMP)-desilylation sequence: Barret, A. G. M.; Cramp, S. M.; Roberts, R. S.; Zecri, F. J. Org. Lett. 2000, 2, 261.

(69) (a) Chinchilla, R.; Dodsworth, D. J.; Nájera, C.; Soriano, J. M.; Yus, M. ES P 00101169, 2001. (b) Chinchilla, R.; Dodsworth, D. J.; Nájera, C.; Soriano, J. M. Tetrahedron Lett. 2001, 42, 7579 . 
(70) Other polymeric HOSu from poly(ethylene-alt-maleic anhydride) cross-linked with diamines has been used for the isolation of polymeric esters: (a) Fridkin, M.; Patchornik, A.; Katchalski, E. Biochemistry 1972, 11, 466. (b) Andreev, S. M.; Tsiryapkin, V. A.; Samoilova, N. A.; Mironova, N. V.; Davidovich, Y. A.; Rogozhin, S. V. Synthesis 1977, 303. (c) Adamczyk, M.; Fishpaugh, J. R.; Mattingly, P. G. Biorg. Med. Chem. Lett. 1999, 9, 217. (d) Adamczyk, M.;

Fishpaugh, J. R.; Mattingly, P. G. Tetrahedron Lett. 1999, 40, 463.

(71) Chinchilla, R.; Dodsworth, D. J.; Nájera, C.; Soriano, J. M. Tetrahedron Lett. 2001, 42, 4487.

(72) Van der Auwera, C.; Van Damme, S.; Anteunis, M. J. O. Int. J. Pept. Protein Res. 1987, 29, 464.

(73) Soriano, J. M. manuscript in preparation.

(74) Chinchilla, R.; Dodsworth, D. J.; Nájera, C.; Soriano, J. M. Tetrahedron Lett. 2000, 41, 2463.

(75) Kalir, R.; Warshawsky, A.; Fridkin, M.; Patchornik, A. Eur. J. Biochem. 1975, 59, 55.

(76) The pyridinium $N$-oxide structure of compound $\mathbf{8 6}$ (HOTT) was determined by Garner et al. by X-ray diffraction analysis, ${ }^{76 a}$ who synthesized HOTT by using phosgene for the preparation of the chlorouronium salt ${ }^{76 a}$ and used this reagent for the preparation of hindered Barton esters: (a) Garner, P.; Anderson, J. T.; Dey, S.; Youngs, W. J.; Galat, K. J. Org. Chem. 1998, 63, 5732. (b) Takasu, K.; Mizutani, S.; Noguchi, M.; Makita, K.; Ihara, M. Org. Lett. 1999, 1, 391. (c) Garner, P.; Anderson, T. Org. Lett. 1999, 1, 1057.
(77) (a) Bailén, M. A.; Chinchilla, R.; Dodsworth, D. J.; Nájera, C.; Soriano, J. M.; Yus, M. In Peptides 1998 Proceedings of the 25th European Peptide Symposium; Bajusz, S.; Hudecz, F., Eds.; Akadémiai Kiadó: Budapest, 1999, 172.

(b) Bailén, M. A.; Chinchilla, R.; Dodsworth, D. J.; Nájera, C. J. Org. Chem. 1999, 64, 8936.

(78) Williams, M. W.; Young, G. T. J. Chem. Soc. 1963, 881.

(79) Chen, S.; Xu, J. Tetrahedron Lett. 1992, 33, 647.

(80) (a) Carpino, L. A.; El-Faham, A.; Minor, C. A.; Albericio, F. J. Chem. Soc., Chem. Commun. 1994, 201. (b) Carpino, L. A.; El-Faham, A. J. Am. Chem. Soc. 1995, 117, 5401.

(81) (a) Bailén, M. A.; Chinchilla, R.; Dodsworth, D. J.; Nájera, C.; Yus, M. ES P 200002651, 2000. (b) Albericio, F.; Bailén, M. A.; Chinchilla, R.; Dodsworth, D. J.; Nájera, C. Tetrahedron 2001, 57, 9607.

(82) Di Fenza, A.; Tancredi, M.; Galoppini, C.; Rovero, P. Tetrahedron Lett. 1998, 39, 8529.

(83) Kovacs, J.; Kim, S.; Holleran, E.; Gorycki, P. J. Org. Chem. 1985, 50, 1497.

(84) Bailén, M. A.; Chinchilla, R.; Dodsworth, D. J.; Nájera, C. Tetrahedron Lett. 2000, 41, 9809.

(85) Bailén, M. A.; Chinchilla, R.; Dodsworth, D. J.; Nájera, C. Tetrahedron Lett. 2001, 42, 5013.

(86) (a) Stula, E. F.; Krauss, W. C. Toxicol. Appl. Pharmacol. 1977, 41, 35. (b) Cross, S.; Moisand, C.; Tollon, Y. Ann. Pharm. Fr. 1972, 30, 585.

(87) (a) Akaji, A.; Kuriyama, N.; Kimura, T.; Fujiwara, Y.; Kiso, Y. Tetrahedron Lett. 1992, 33, 3177. (b) Kiso, Y.; Kimura, T.; Fujiwara, Y.; Sakikawa, H.; Akaji, A. Chem. Pharm. Bull. 1990, 38, 270. 